\title{
Depletion of conventional mature B cells and compromised specific antibody response in bovine immunoglobulin $\mu$ heavy-chain transgenic mice
}

\author{
Min ZHANG ${ }^{1 *}$, Xueqian CHENG ${ }^{1 *}$, Dan $\mathrm{CHU}^{1}$, Jingwen LIANG ${ }^{1}$, Yi SUN ${ }^{1}, \mathrm{Li} \mathrm{MA}^{1}$, Beilei XU ${ }^{1}$, Min ZHENG ${ }^{2}$, \\ Meili WANG ${ }^{2}$, Liming REN ${ }^{1}$, Xiaoxiang HU $^{1}$, Qingyong MENG ${ }^{1}$, Ran ZHANG ${ }^{1}$, Ying GUO ${ }^{1}$, Yunping DAI ${ }^{1}$, \\ Robert AITKEN ${ }^{3}$, Ning LI ${ }^{1}$, Yaofeng ZHAO $(\bowtie)^{1,4}$ \\ 1 State Key Laboratory of Agrobiotechnology, College of Biological Sciences, China Agricultural University, Beijing 100193, China \\ 2 GeneProtein Biotech Ltd, Beijing 100193, China \\ 3 School of Life Sciences, College of Medical, Veterinary and Life Sciences, University of Glasgow, Glasgow, UK \\ 4 Key Laboratory of Animal Reproduction and Germplasm Enhancement in Universities of Shandong, College of Animal Science and Technology, \\ Qingdao Agricultural University, Qingdao 266109, China
}

\begin{abstract}
In this study, we introduced the bovine immunoglobulin $\mu$ heavy-chain gene (the orphaned gene on BTA11) into mouse germline cells. Bovine IgM was highly expressed in selected transgenic lines, and it largely inhibited rearrangements of the endogenous immunoglobulin heavy chain $(\operatorname{IgH})$ genes in these lines. The forced expression of bovine IgM resulted in reduced numbers of pro- and pre-B cells but increased the number of immature $\mathrm{B}$ cells in the transgenic mice. Bovine IgM-expressing B cells can migrate from the bone marrow to the spleen, but most of the cells are arrested at the $\mathrm{T} 1$ transitional $\mathrm{B}$ cell stage, leading to a significantly lower number of $\mathrm{T} 2$ transitional and mature B cells in the spleen. Although the serum concentrations of endogenous $\operatorname{IgM}$ and $\operatorname{IgG}$ in the transgenic mice were significantly decreased, the IgA levels were slightly increased compared to the WT mice. The bovine IgM level in the serum was only one-tenth to one-fifth of that of endogenous mouse IgM, suggesting that most of the serum immunoglobulin were contributed by endogenous IgH gene-expressing B cells. These transgenic mice also exhibited a lower frequency of unique complementarity determining region 3 (CDR3) sequences in their $\mathrm{VH}$ repertoire and $\mathrm{V} \kappa$ repertoire but exhibited an increased frequency of unique CDR3 in their $\mathrm{V} \lambda$ repertoire. Compared to the WT mice, the transgenic mice had a significantly higher percentage of mouse IgMexpressing B cells that expressed $\lambda$ chains. Finally, we showed that the transgenic mice were deficient in a specific
\end{abstract}

Received August 1, 2014; accepted August 18, 2014

Correspondence: yaofengzhao@cau.edu.cn

${ }^{*}$ These authors contribute equally to the work antibody response to antigen stimulation.

Keywords bovine Ig $\mu$ heavy-chain, transgenic mice, B cell development, allelic exclusion, immune response, Ig repertoire

\section{Introduction}

B cells are one of the defining features of the immune systems of jawed vertebrates, and they are responsible for the production of a highly diverse repertoire of immunoglobulins that are essential in defending the host against the invading pathogens that the animal confronts during its lifetime $[1,2]$. In humans and mice, B cell development is strictly regulated and is tightly associated with the expression of surface immunoglobulins, or B cell receptors (BCR) [3]. In early pro-B cells, the rearrangement of the diversity gene segments (DH) and joining gene segments $(\mathrm{JH})$ of heavy chain takes place on both immunoglobulin heavy chain ( $\operatorname{IgH})$ alleles [4] and is followed by the addition of the variable gene segments of heavy chain (VH) to the newly-formed DH-JH segment to generate a complete exon that encodes the variable region of an $\mathrm{IgH}$ in late pro-B cells. Successfully transcribed and translated $\mathrm{IgH}$ proteins are tested for functionality by pairing with a surrogate light chain (SLC), thereby creating a pre-BCR in large pre-B cells. The interaction of $\operatorname{Ig} \alpha / \operatorname{Ig} \beta$ with the preBCR drives further B cell development and the initiation of Ig light chain ( $\operatorname{IgL})$ rearrangement [5-8]. The successful expression of an IgL and its assembly with the IgM heavy chain creates a true BCR (IgM isotype), an essential surface marker of immature B cells in the bone marrow. 
The immature B cells then migrate from the bone marrow to the peripheral lymphoid organs, where they reach maturity and begin co-expressing surface $\operatorname{IgM}$ and $\operatorname{IgD}$.

During B cell development, a series of regulatory mechanisms and checkpoints guarantees the proper expression of the $\mathrm{BCR}$, which in turn signals further $\mathrm{B}$ cell differentiation. Although DH-JH rearrangement is initiated on both $\operatorname{IgH}$ alleles in early pro-B cells [4], successful assembly of VH with DH-JH usually occurs for only one IgH allele, thus ensuring the mono-specificity of the BCR in a given B cell, a phenomenon known as "allelic exclusion" $[9,10]$. Although many models have been proposed for allelic exclusion, it is now generally accepted that feedback inhibition from the translation of the successfully rearranged first allele and the binding of its protein product to the SLC functions to prevent further $\mathrm{VH}$ to $\mathrm{DH}-\mathrm{JH}$ rearrangement of the other allele [11]. A large number of studies using transgenic mice have demonstrated that expression of the membrane-bound forms of IgH genes (including $\mu, \delta$ and $\gamma$ ) is able to mediate allelic exclusion. One prerequisite for the feedback model is that the rearranged allele must be transcribed and, more essentially, translated to produce heavy chain products that bind to SLCs to form the pre-BCR. This requirement was challenged by a recent study that used transgenic mice to demonstrate that the accumulation of non-translatable IgH mRNA in early pro-B cells was able to mediate allelic exclusion [12]. These data argue that feedback inhibition by pre-BCR may not be the only mechanism responsible for IgH allelic exclusion [12].

The elucidation of IgH allelic exclusion has benefited from the generation of large numbers of transgenic mouse lines [13-17] in which rearranged human or mouse $\operatorname{IgH}$ genes were randomly introduced into the mouse genome, typically at locations separate from the endogenous $\operatorname{IgH}$ locus. These genetic modifications created two IgH loci on different chromosomes. In addition to inhibition of rearrangements at the endogenous IgH loci, the expression of transgenic $\mathrm{IgH}$ genes has also been reported to cause severe $\mathrm{B}$ cell deficiency $[18,19]$. However, the mechanisms behind this phenomenon are unclear.

In the work reported here, we have chosen to explore these effects using an IgH locus that is phylogenetically distant from systems used thus far. Although IgM is the sole antibody class expressed in all jawed vertebrates and is structurally conserved [2], bovine $\operatorname{IgM}$ is relatively distinct from IgM of mice and humans in sequence and phylogeny [20] and hence its ability to exercise allelic exclusion with the endogenous loci of the mouse is potentially informative.

The generation of transgenic mouse lines carrying an IgM locus from cattle also has the potential to explore aspects of bovine immunology. In mammals, the coexistence of two functional IgH loci has rarely been observed, but cattle, and perhaps sheep, are notable exceptions $[21,22]$. In cattle, it has long been recognized that a $\mu$ gene is present on Bos taurus autosome (BTA) 11, whereas the major bovine $\operatorname{IgH}$ locus (encoding $\operatorname{IgM}$, IgG, $\operatorname{IgD}$, IgE and $\operatorname{IgA}$ ) maps to BTA 21 [23]. Initially, the $\mu$ gene on BTA 11 was thought to be a pseudogene [21]. However, recent studies have revealed that it can be functionally expressed, albeit at very low levels [24]. We recently sequenced a bacterial artificial chromosome (BAC) clone (944D11) that contained the $\mu$ gene from BTA 11 and demonstrated that the $\mu$ gene appeared to be structurally intact and functional. However, there is a pseudo- $\delta$ gene downstream of the $\mu$ gene, and additional IgH constant region (IGHC) genes could not be located. Nonetheless, structurally intact DH and JH gene segments were found upstream of the $\mu$ gene. Our study therefore addresses the ability of this locus to undergo rearrangement and expression and thereby contribute in a significant way to the functional repertoire of the host.

\section{Materials and methods}

\subsection{Ethics statement}

All animal work was conducted according to the guidelines for the care and use of experimental animals established by the Ministry of Science and Technology of the People's Republic of China (Approval number: 2006-398).

\subsection{Bovine BAC clone and the construction of transgenic $\mathrm{BAC}$ vectors}

The bovine BAC clone 944D11 was previously isolated from a genomic BAC library $[25,26]$. On the basis of the $\mathrm{BAC}$ clone, we designed two transgenic $\mathrm{BAC}$ vectors (mVH-bBAC and mPL-bVH-bBAC) with genetic modifications.

To make the mVH-bBAC construct, the mouse VH segment was amplified from the tail DNA of C57BL/6 mice by PCR with primers J558.67.166-Promoter1 and J558.67.166-VHas2 (Appendix A-Table S1). The product comprised the VH-J558 lymphocyte-specific VH promoter, the complete $\mathrm{VH}$ segment and the recombination signal sequence (RSS) at the downstream terminus of the segment. Homologous arms for recombination were then added to the fragment by PCR with another set of primers: 6801-P1 and 7861-V2 (Appendix A-Table S1). As a result, the complete upper arm was comprised of a Nhe I site, an 80-bp BAC DNA sequence and an EcoR I site, whereas the lower arm was comprised of an 80-bp BAC DNA sequence and a Nhe I site. An FRT-zeocin cassette was then introduced into the upper homologous arm in the EcoR I site. Next, the BAC DNA was modified with the recombined DNA fragment using the classical phage $\lambda$ red homologous recombination system. The Zeocin cassette between the two FRT sites was excised using the FLP recombination system. Finally, the site-specific 
integration of the mouse $\mathrm{VH}$ segment into the $\mathrm{BAC}$ was confirmed by PCR with two sets of primers: F-6739 with R-7110 and F-8594 with R-9175 (Appendix A-Table S1).

To make the mPL-bVH-bBAC construct, a mouse genomic segment (termed mPL) including the promoter and a leader peptide-encoding sequence was produced by PCR with primers J558.67.166-Promoter1 and mouse VJ558.67.166-Leaderas (Appendix A-Table S1). A rearranged bovine VDJ fragment was amplified from Holstein cattle spleen cDNA by PCR with primers specific for the bovine VH segments and JH6 segment, respectively. The bovine VDJ fragment was fused to the mouse PL segment via fusion PCR and subsequently cloned into the PMD 19-T vector (Takara, Dalian) and sequenced. Homologous arms for recombination were then added to the fragment by PCR with another set of primers: 54064-P1 and 56092JH6as (Appendix A-Table S1). The resulting fragment was used to replace the bovine JH locus in the BAC clone with a strategy similar to that used to generate the $\mathrm{mVH}-\mathrm{bBAC}$ construct. The site-specific integration of the bovine VDJ fragment into the BAC was also confirmed by PCR with two sets of primers: F-53926 with R-54263 and F-55797 with R-56214 (Appendix A-Table S1). All of the PCR products were cloned into PMD 19-T vectors (Takara) and sequenced.

\subsection{Generation and identification of transgenic mice}

DNA representing two modified BAC constructs was prepared with a NucleoBond Xtra Maxi Kit following the manufacturer's protocol (Macherey-Nagel, Düren), digested with Not I and separated on a $1 \%$ agarose gel using the CHEF-DR III system (Bio-Rad). The BAC insert DNA was subsequently purified by electroelution with dialysis and dissolved in injection buffer. The purified BAC DNA was microinjected into the pronuclei of fertilized Kunming-White eggs following standard protocols.

Genomic DNA was isolated from tail biopsies of $\mathrm{F}_{0}$ generation mice by phenol/chloroform extraction, and the integrity of the two transgenes was confirmed by PCR with several pairs of primers.

To perform Southern blotting, $20 \mu \mathrm{g}$ of genomic DNA was digested with $\mathrm{Sac}$ I (Promega, USA) and hybridized to the bovine constant region exon 1 to 2 of heavy chain (CH1-2) with a DIG-labeled probe. The probe was produced by PCR with probe- $F$ and probe-R primers. Hybridization and detection were performed using a DIG High Prime DNA Labeling and Detection Starter Kit II following the manufacturer's instructions (Roche). Transgenic mouse lines were propagated by mating positive $\mathrm{F}_{0}$ mice with WT mice.

\subsection{Genome walking}

The insertion site of bovine BAC DNA in mice was confirmed by genome walking. According to the manufacturer's instructions of the genome walking kit (Clontech, CA, USA), amplifications from 3'- ends of the BAC DNA were achieved by nest-PCR with two sets of primers: F-126849 with AP1 and F-126886 with AP2 (Appendix ATable S1). All amplifications were using LA Taq DNA polymerase (Takara, Dalian, China). All of the PCR products were cloned into PMD 19-T vectors (Takara) and sequenced.

2.5 RNA isolation and RT-PCR analysis of transgene expression

Total RNA samples were isolated from various tissues of 8- to 16-week-old positive mice using TRIzol reagent (Kangwei Biotech, Chongqing), and reverse transcription was performed using M-MLV Reverse Transcriptase following the manufacturer's instructions (Promega, USA). RT-PCR was used to examine the tissue-specific expression of bIgM using the bovine JH6-forward and bovine $\mathrm{C} \mu 1$-reverse primers specific to the bovine $\mu \mathrm{CH} 1$ exon. Mouse $\beta$-actin was amplified as an internal control with primers $\mathrm{F}$ and $\mathrm{R}$. The $\mathrm{mVH}$ transgene expression was examined by PCR with mouse-FVH and bovine-RCH1 primers, whereas bovine IgM expression was detected by $\mathrm{PCR}$ with $\mathrm{bFCH} 2$ and $\mathrm{bRCH} 2$ primers (Appendix A-Table S1) specific to the bovine $\mu \mathrm{CH} 2$ exon. Furthermore, the VDJ sequence of the bovine IgM transcripts was amplified by $5^{\prime}$ RACE with bC $\mu$-GSP2 and bC $\mu$-GSP3 primers (Appendix A-Table S1) specific to the bovine $\mu \mathrm{CH} 1$ exon, following the manufacturer's protocol (Invitrogen, USA).

\subsection{Detection of trans-spliced RNA}

IgH transcripts derived from the trans-splicing of the bovine $\mathrm{VH}$ and endogenous mouse constant genes were detected by RT-PCR. Chimeric IgA transcripts were detected with the primers bVH3 and $\mathrm{mC} \alpha-2$ (Appendix A-Table S1). Similarly, chimeric IgG transcripts were detected with the primers $\mathrm{bVH} 3$ and $\mathrm{mC} \gamma$ (Appendix ATable $\mathrm{S} 1$ ). The sequence of $\mathrm{mC} \gamma$ was conserved among the mouse $\mathrm{C} \gamma 1, \mathrm{C} \gamma 2 \mathrm{~b}$ and $\mathrm{C} \gamma 3$ genes. Chimeric IgD transcripts were examined via nested PCR with the primers bVH1 and $\mathrm{mC} \delta-2$, as well as bVH3 and $\mathrm{mC} \delta-3$ (Appendix ATable S1).

\subsection{Western blotting}

The serum samples collected from 8- to 16-week-old transgenic mice were separated by SDS-PAGE, electrophoretically transferred onto Immobilon-P membranes (Millipore, Billerica, MA) and treated following a standard protocol. Immunodetection was conducted with HRPconjugated antibodies, including goat anti-mouse $\operatorname{IgM}(\mu$ chain) (Rockland Immunochemicals, Gilbertsville, PA), 
goat anti-bovine IgM ( $\mu$ chain) (KPL, Gaithersburg, Maryland), rabbit anti-mouse kappa chain (Acris $\mathrm{GmbH}$, Herford) and rabbit anti-mouse lamda chain (Acris $\mathrm{GmbH}$, Herford). Enhanced chemiluminescence and autoradiography were performed using ECL western blotting reagents (Amersham Biosciences, UK). Serum samples from agematched WT mice served as negative controls.

\subsection{Flow cytometry analysis}

Single-cell suspensions were prepared by passing tissue samples through $200-\mu \mathrm{m}$ nylon mesh and resuspending the filtered cells in PBS. Erythrocytes were lysed in $1 \times \mathrm{RBC}$ lysis buffer (eBioscience, San Diego, CA). For three-color fluorescence surface staining, approximately $10^{6}$ cells per sample were incubated with varying antibody combinations according to a standard protocol. The labeled antibodies included FITC anti-bovine IgM (AbD Serotec, UK), FITC anti-mouse IgM (eBioscience), PE anti-mouse IgM (Biolegend, San Diego, CA), PE anti-mouse CD43 (eBioscience), PE anti-mouse IgD (eBioscience), PE antimouse kappa chain (Acris Antibodies $\mathrm{GmbH}$ ), PE antimouse lamda chain (Biolegend), PerCP/cy5.5 anti-mouse kappa chain (BD Biosciences, San Jose, CA), PE antimouse CD138 (BD Biosciences), PE anti-mouse CD21/ CD35 (eBioscience) and PE/cy5.5 anti-mouse B220 (CD45R) (eBioscience).

The cells were collected from the transgenic mice at 8 to 16 weeks of age in parallel with age-matched controls. Twenty thousand cells were collected for each sample. All of the data were acquired on a MoFlo flow cytometer and analyzed using Summit software (Beckman Coulter, Fullerton, CA).

\subsection{OVA immunization and ELISA}

The OVA antigen (ovalbumin, Sigma, USA) was resuspended in Montanide ISA 70 adjuvant (1:1). Then, 6- to 8week-old mice from two transgenic lines and the WT group were intramuscularly immunized with $1 \mu \mathrm{g} \cdot \mu \mathrm{L}^{-1}$ OVA twice. Each group included four mice. All of the mice received a primary injection on day 0 and a secondary injection on day 14. Serum samples were collected on day 21 and examined using mouse anti-OVA IgG and antiOVA IgM Elisa Kit respectively following the manufacturer's instructions (ADI, San Antonio,Texas). The serum anti-OVA IgG concentration was determined from dilutions of 1:150000 (transgenic mice) or 1:30000 (WT mice), while the serum anti-OVA IgM concentration was determined from dilutions of 1:100 (transgenic mice) or 1:10 (WT mice). The serum levels of pre- and postimmunization mice in different groups were measured using ELISA kits for mouse IgM, IgG and IgA and bovine IgM following the manufacturer's instructions (ADI, San Antonio, Texas).
2.10 Amplification and repertoire analysis of rearranged endogenous mouse VH and variable gene of light chain (VL) genes from the spleen

For VH gene amplification, PCR was performed using a pool of 16 equivalent $\mathrm{VH}$ family forward primers and the reverse primer $\mathrm{C} \mu$. For VL amplifications, splenocytes that were positive for transgenic bovine IgM and mouse $\operatorname{IgM}$ were sorted by flow cytometry (Beckman Coulter), and total RNA was extracted using an RNeasy Mini Kit (Qiagen, Armenia) and an RNase-Free DNase Kit (Qiagen). Reverse transcription was performed with SuperScript III Reverse Transcriptase following the manufacturer's instructions (Promega). PCR amplification was performed using Phusion DNA polymerase (NEB, Ipswich, MA). The oligonucleotide primers used for reverse transcription were RTCK and RTC $\lambda$. The forward primers used for $\mathrm{V} \kappa$ and $\mathrm{V} \lambda$ detection were pools of $19 \mathrm{V \kappa}$ and $8 \mathrm{~V} \lambda$ primers, and the reverse primers were $\mathrm{C} \kappa$ and $\mathrm{C} \lambda$, respectively (Appendix A-Table S1).

\subsection{Statistical analysis}

The statistical analyses in this study were performed using two-tailed Student $t$-tests and Chi-square tests.

\section{Results}

3.1 Construction of transgenic BAC vectors and the generation of transgenic mice

The bovine BAC clone 944D11 was previously isolated from a genomic BAC library [25] and sequenced using a shotgun-based approach. The BAC was shown to contain $\mathrm{DH}$ and $\mathrm{JH}$ segments, as well as an intact $\mu$ and a pseudo- $\delta$ gene. Using the backbone of this BAC clone, we designed two transgenic BAC vectors (mVH-bBAC and mPL-bVHbBAC) with genetic modifications (Fig. 1). In mVHbBAC, a mouse $\mathrm{VH}$ segment consisting of a $\mathrm{VH}$ promoter, a $\mathrm{VH}$ coding sequence and an intact recombination signal sequence was inserted upstream of the bovine DH locus. Therefore, rearrangement and expression of this construct has the potential to generate a chimeric mouse-bovine $\mathrm{IgH}$. In the second construct, mPL-bVH-bBAC, a fused genomic fragment consisting of a mouse $\mathrm{VH}$ promoter and a rearranged bovine VDJ exon was used to replace the $\mathrm{JH}$ locus in the original BAC, thereby creating the potential for expression of a bovine IgH. The construction details are shown in Appendix B-Fig. S1.

The inserts for the two constructs (mVH-bBAC and mPL-bVH-bBAC) were isolated from the BAC vector by Not I digestion and used to create transgenic mice by microinjection. Mice of the $\mathrm{F}_{0}$ generation were examined for the presence of transgenes by both PCR and Southern blotting (Fig. 2). Five mice (Founders 1, 2, 8, 9 and 10) out 
(a) $100 \mathrm{bp}$

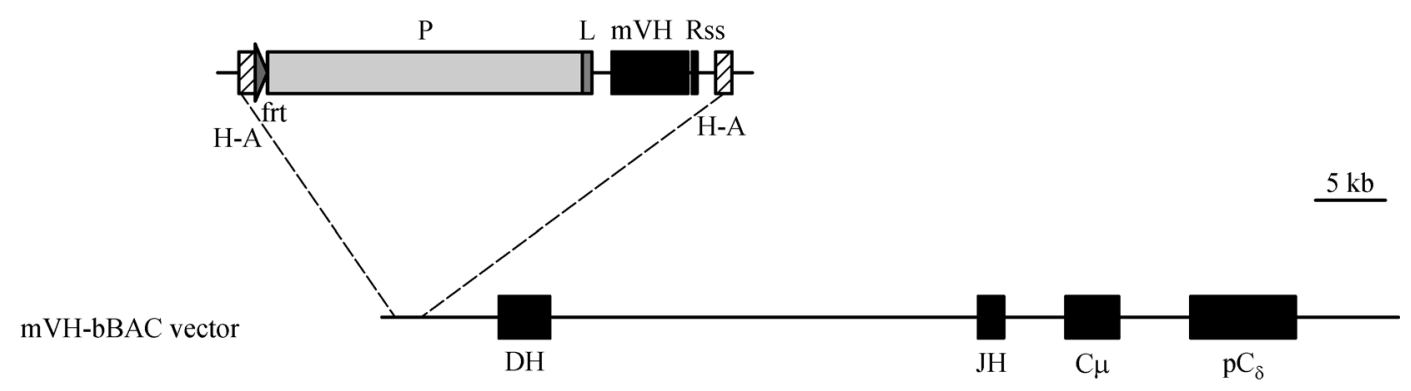

(b)

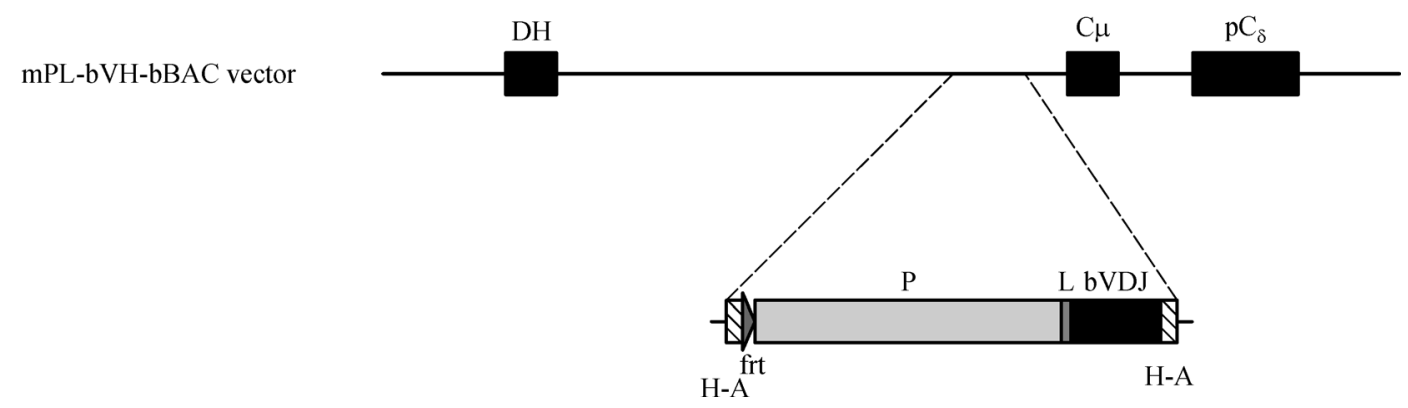

Fig. 1 Schematic map of the two modified transgenic BAC vectors. (a) mVH-bBAC vector; (b) mPL-bVH-bBAC vector. Gene elements are indicated by different boxes. P, L and RSS denote the promoter, leader peptide and recombination signal sequence, respectively. Squares with differently hatched fills, abbreviated as H-A, indicate homologous arms. The FRT elements are depicted as triangles. Heavy chain variable $(\mathrm{VH})$, diversity $(\mathrm{DH})$, joining $(\mathrm{JH})$ and constant $(\mathrm{CH})$ region coding segments are shown as black squares. The proportional scales for the two transgenes are also indicated.

of 23 tested were mVH-bBAC-positive (Fig. 2a), whereas 8 (Founders 7, 14, 15, 19, 22, 24, 27 and 31) out of an additional 31 mice had the mPL-bVH-bBAC transgene (Fig. 2b).

The aforementioned transgenic founders were mated with WT mice, and the expression of bovine IgM in the resulting transgenic offspring was examined by RT-PCR and flow cytometry. RT-PCR detected bovine IgM heavychain transcripts in all transgenic lines and therefore the bovine DH and $\mathrm{JH}$ segments present on BTA 11 are capable of undergoing rearrangement. However, very little surface bovine IgM could be detected on the B cells in any mVH-bBAC transgenic mouse. B cell development was largely unaffected by the transgene in $\mathrm{mVH}-\mathrm{bBAC}$ mice compared to the WT mice. In two lines of mPL-bVHbBAC transgenic mice (Lines 15 and 22), the bovine IgM was highly expressed on most splenic B cells, and B cell development was remarkably disturbed in these mice. These two transgenic lines were thus chosen for further investigation in subsequent experiments. At the same time, the mPL-bVH-bBAC transgene was located on mouse chromosome 14 using genome walking.

(a)

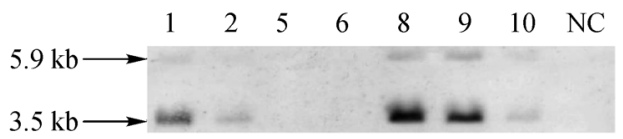

(b)

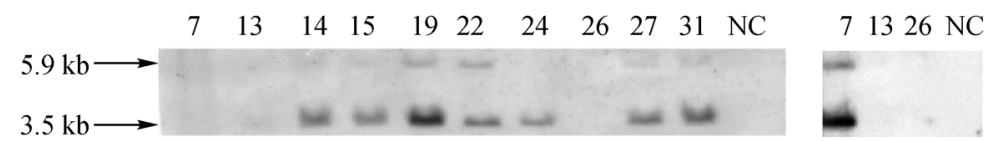

Fig. 2 Southern blot analysis of the transgenic mice. (a) Analysis of the founders of the mVH-bBAC vector transgenic lines; (b) analysis of the founders of the mPL-bVH-bBAC vector transgenic lines. The hybridized $\mu$ and pseudo- $\delta$ genes are 3.5 and $5.9 \mathrm{~kb}$ in length, respectively; The genomic DNA of a WT mouse is used as a negative control (NC); Line 7 was shown to be transgene-positive by PCR and another Southern blotting experiment. 
3.2 B cell development is altered by high bovine IgM expression levels

To examine B cell development in the transgenic mice, a series of antibodies against B cell surface markers was utilized to characterize the $\mathrm{B}$ cell populations in the bone marrow, spleen and peripheral blood leukocytes (PBL). In transgenic lines with low levels of bovine IgM expression, the expression of endogenous mouse IgM was nearly normal. Correspondingly, the percentages of different B cell subsets in these mice were nearly the same as those in WT mice (data not shown). However, the expression of endogenous mouse IgM was severely diminished in the two mPL-bVH-bBAC transgenic lines (Lines 15 and 22) that highly expressed bovine IgM (Fig. 3). In Lines 15 and 22, the expression of the bovine VH (with VDJ already rearranged in the germline) was driven by a mouse B cellspecific VH promoter. These data suggest that allelic exclusion was largely enforced by the expression of transgenic bovine $\operatorname{IgM}$ in Lines 15 and 22 despite the sequence differences between bovine and murine $\operatorname{IgM}$. Anti-CD43 and anti-mouse IgM antibody staining of bone marrow B cells from the transgenic mice indicated that the proportion of immature B cells was markedly reduced compared to that in WT mice $(2.9 \% \pm 0.7 \%$ vs. $24.3 \% \pm$ $3.7 \%, P<0.001)$. The proportions of pro-and pre-B cells were also significantly different in the two groups $(P<0.01$ and $P<0.001$, respectively) (Fig. 3a and Fig. $3 \mathrm{~d})$. Pro- and pre-B cells were detected at remarkably decreased levels when anti-bovine IgM antibody was used to identify these subsets. However, the proportion of immature B cells (expressing bovine IgM) was significantly increased by roughly twofold $(56.7 \% \pm 6.9 \%$ vs. $24.3 \% \pm 3.7 \%, P<0.01$ ) (Fig. 3a and Fig. 3d). Therefore, the forced expression of bovine IgM appeared to facilitate the development of B cells from pro- and pre-B cells to immature B cells in the bone marrow.

Splenic B cells can be categorized as transitional (T1 and T2) or mature B cells based on their surface expression of IgM and IgD [27,28]. In WT mice, mature B cells $\left(\operatorname{IgD}^{+} \operatorname{IgM}{ }^{-}\right)$account for a large portion of the $\mathrm{B}$ cells in the spleen, whereas $\mathrm{T} 1\left(\operatorname{IgD}^{-} \operatorname{IgM}^{+}\right)$and $\mathrm{T} 2\left(\operatorname{IgD}^{+} \operatorname{IgM}^{+}\right) \mathrm{B}$ cells together account for approximately half of the mature $\mathrm{B}$ cells (Fig. 3b). Using mouse $\operatorname{IgD}$ and $\operatorname{IgM}$ as surface markers, mature $\mathrm{B}$ cells were found to be almost completely depleted in transgenic mice $(2.1 \% \pm 1.1 \%$ vs. $60.3 \% \pm 5.4 \%, P<0.001)$. In addition, markedly fewer T2 $\mathrm{B}$ cells were detected in the spleens of transgenic mice $(4.0 \% \pm 1.0 \%$ vs. $8.6 \% \pm 3.2 \%, P<0.01)$, though the proportion of $\mathrm{T} 1 \mathrm{~B}$ cells expressing mouse IgM was not significantly different from that in WT mice $(14.0 \% \pm 2.4 \%$ vs. $14.0 \% \pm 3.2 \%, P>0.05$ ) (Fig. 3b and Fig. 3e). Similarly, when mouse $\operatorname{IgD}$ and bovine $\operatorname{IgM}$ were used as surface markers, very few mature B cells $(2.6 \% \pm 1.2 \%$ vs. $60.0 \% \pm 2.4 \%, P<0.001)$ and fewer T2 B cells $(5.4 \% \pm$ $2.3 \%$ vs. $8.6 \% \pm 3.2 \%, P<0.05)$ were detected. A large portion of B cells $(70.0 \% \pm 4.7 \%)$ expressed bovine IgM and was arrested at the T1 stage (Fig. $3 \mathrm{~b}$ and Fig. 3e). The near depletion of mature $\mathrm{B}$ cells was also confirmed using CD21 as a surface marker [27], though the T2 population accounted for a higher percentage in this analysis (Fig. 4a and Fig. $4 \mathrm{~b}$ ) than in the analysis using bovine $\operatorname{IgM}$ and mouse IgD. Nonetheless, the analysis using CD21 also demonstrated that most bovine IgM-expressing B cells were blocked at the T1 stage. Further, our analysis demonstrated that a small portion of splenic $(10.0 \% \pm$ $2.9 \%)$ and blood $(6.6 \% \pm 0.9 \%) \mathrm{B}$ cells in transgenic mice expressed both bovine IgM and murine $\operatorname{IgM}$ on their surfaces (Fig. 4c).

3.3 Detection of endogenous immunoglobulins and bovine $\operatorname{IgM}$ in the serum of transgenic mice

The concentrations of total endogenous $\operatorname{IgM}, \operatorname{IgG}$ and $\operatorname{Ig} \mathrm{A}$ and bovine $\operatorname{IgM}$ in both transgenic and WT mice were examined by ELISA. In transgenic Line 15, the concentrations of endogenous $\operatorname{IgM}$ and $\operatorname{IgG}$ were reduced to approximately one-third and one-half of those in WT mice, respectively $(P<0.05)$ (Fig. 5a), whereas the IgA level appeared to be slightly increased $(P>0.05)$ (Fig. 5a). Although the bovine IgM-expressing B cells represented a large proportion of the B cells in the bone marrow, spleen and PBL, the concentration of bovine IgM in the serum was only approximately one-tenth of that of the endogenous mouse IgM concentration (Fig. 5b), likely because most of the bovine IgM-positive B cells were arrested at the T1 stage and could not develop into mature B cells or plasma cells.

Although the percentages of mature B cells in the transgenic mice were significantly reduced to approximately $1 / 20$ to $1 / 40$ of those of the WT mice, the levels of the different mouse Ig classes in the serum were not affected to a proportional extent. We analyzed the percentages of plasma cells in different tissues of transgenic and WT mice and found that the values in the transgenic mice were approximately $60 \%-75 \%$ of those in the WT mice (in the bone marrow: $0.40 \% \pm 0.03 \%$ vs. $0.63 \% \pm 0.06 \%, P<0.001$. in the spleen: $1.12 \% \pm 0.19 \%$ vs. $1.49 \% \pm 0.23 \%, P<0.05$; and in the PBL: $0.37 \% \pm$ $0.03 \%$ vs. $0.44 \% \pm 0.05 \%, P<0.05)$. The number of total $\mathrm{B}$ cells in the bone marrow, spleen and PBL in Lines 15 and 22 was reduced to approximately $40 \%-75 \%$ of that of WT mice (in the bone marrow: $4.65 \% \pm 0.48 \%$ vs. $7.72 \% \pm$ $0.78 \%, P<0.001$; in the spleen: $29.0 \% \pm 6.3 \%$ vs. $40.0 \% \pm$ $4.5 \%, P<0.05$; and in the PBL: $4.6 \% \pm 1.1 \%$ vs. $10.6 \% \pm$ $1.4 \%, P<0.01$ ) (Fig. 6).

3.4 Bovine IgM high-expressing transgenic mice are deficient in the specific IgG antibody response

Two groups of mice (Line 15 and WT, five mice for each group), aged 6 to 8 weeks, were intramuscularly 
(a)
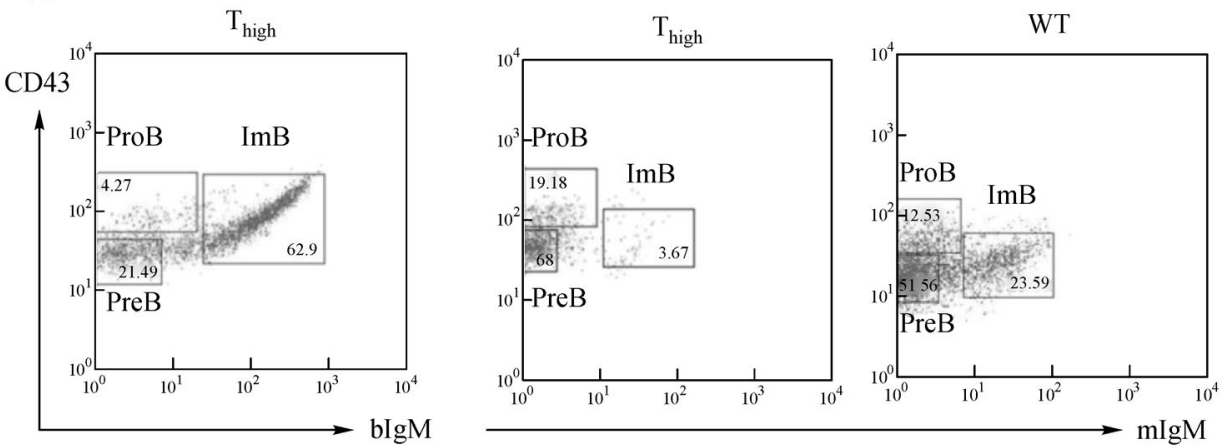

Bone

marrow

(b)
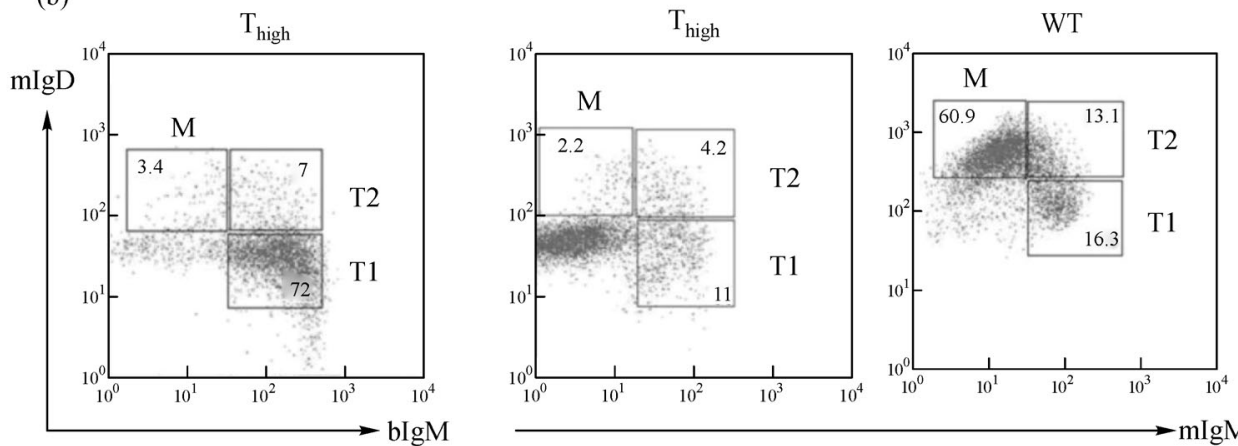

Spleen

(c)
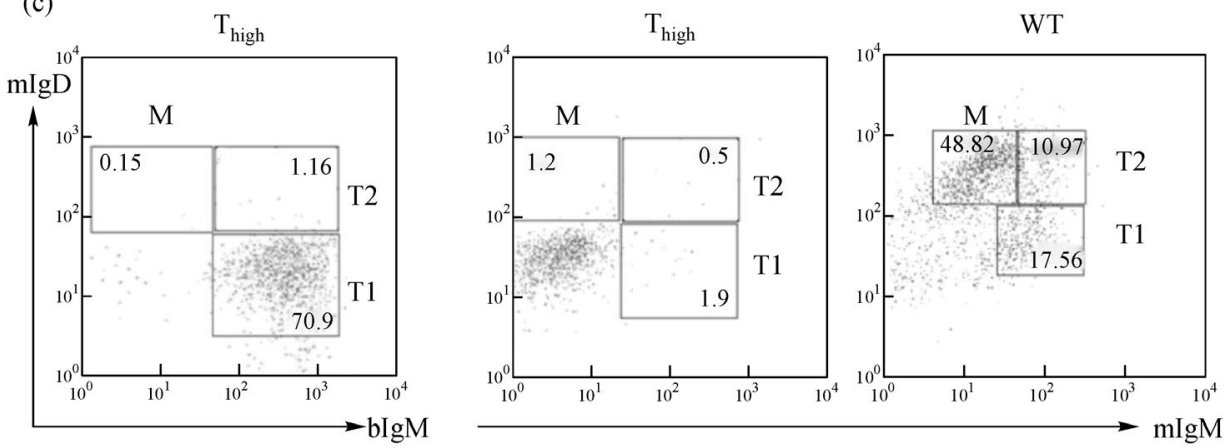

PBLs

(d)

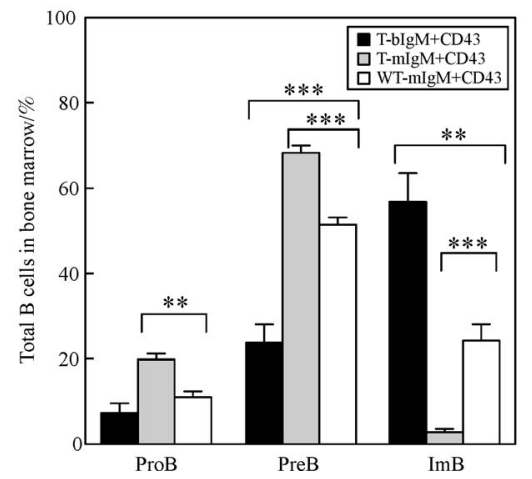

(e)

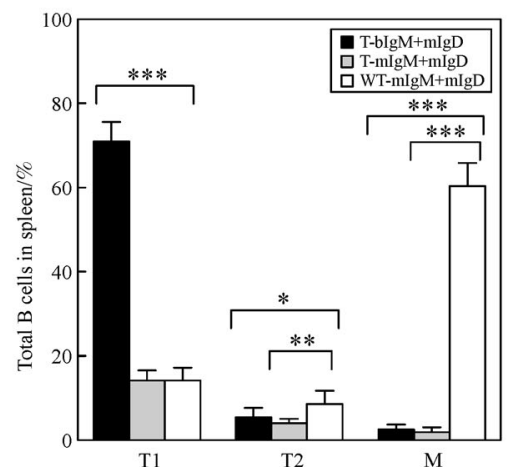

Fig. 3 Flow cytometry analysis of B cell populations in the bone marrow, spleen and PBL of transgenic ( $\left.\mathrm{T}_{\text {high }}\right)$ and WT mice. (a) Measurements of three cell subsets in bone marrow. The percentages of pro-B (B220 $\left.{ }^{+} \mathrm{CD} 43^{+} \operatorname{IgM}\right)$, pre-B $\left(\mathrm{B} 220^{+} \mathrm{CD} 43{ }^{-} \mathrm{IgM}\right)$ and immature $\mathrm{B}\left(\mathrm{B} 220^{+} \mathrm{CD} 43 \mathrm{IgM}^{+}\right)$cells are indicated in each gate; (b) measurements of the three cell subsets were taken in the spleen; (c) measurements of the three cell subsets were taken the PBL. The percentages of $\mathrm{T} 1\left(\mathrm{~B} 220^{+} \operatorname{IgD} \operatorname{IgM}{ }^{+}\right), \mathrm{T}_{2}\left(\mathrm{~B}_{2} 20^{+} \mathrm{IgD}^{+} \operatorname{IgM}{ }^{+}\right)$and mature $\left(\mathrm{B} 220^{+} \mathrm{IgD}^{+} \mathrm{IgM}\right) \mathrm{B}$ cells are indicated in each gate. Each set contains data from transgenic $\left(\mathrm{T}_{\text {high }}\right)$ and WT animals, respectively. A total of 20000 events were collected for each sample. Plots are representative of measurements in at least five individual mice; (d) statistical analysis of bone marrow B cell subset percentages in subfigure a with black, gray and white bars representing transgenic mice with anti-bovine IgM antibody, transgenic mice with anti-mouse IgM antibody and WT mice with anti-mouse IgM antibody, respectively; (e) statistical analysis of B cell subset percentages in the spleen based on subfigure $\mathrm{b}$. Significance values were determined by a two-tailed Student $t$ test (*: $P<0.05, * *: P<0.01, * * *: P<0.001)$. 


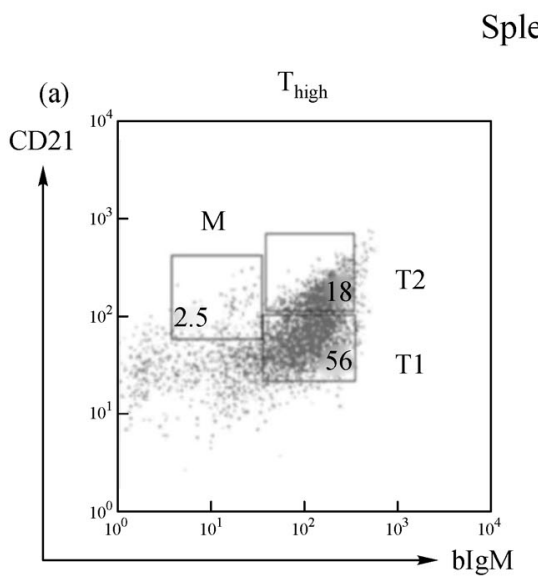

Spleen
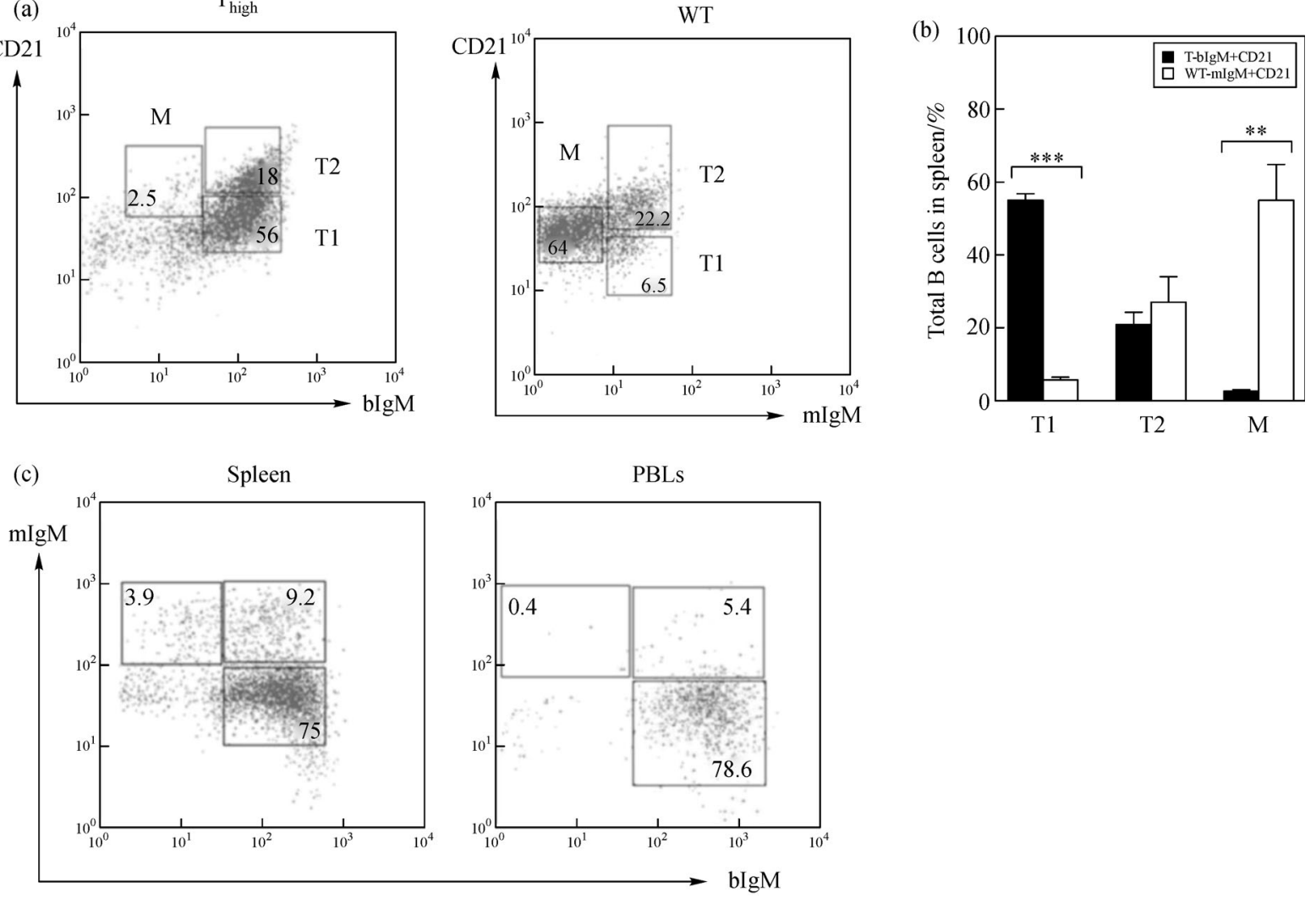

Fig. 4 Flow cytometry analysis of splenic lymphocytes from transgenic $\left(\mathrm{T}_{\text {high }}\right)$ and WT mice. (a) Cells were stained for B220, IgM (bIgM/mIgM) and CD21, and the proportion of the cell population corresponding to $\mathrm{T} 1\left(\mathrm{~B} 220^{+} \mathrm{CD} 21{ }^{-} \mathrm{IgM}^{+}\right), \mathrm{T}^{2}\left(\mathrm{~B} 220^{+} \mathrm{CD} 21^{+} \mathrm{IgM}{ }^{+}\right)$ and mature $\left(\mathrm{B} 220^{+} \mathrm{CD} 21^{+} \mathrm{IgM}\right) \mathrm{B}$ cells is indicated for each gate. The data are representative of four independent samples; (b) statistical analysis of T1, T2 and mature B cells in transgenic and WT mice by two-tailed Student $t$ tests $(* *: P<0.01, * * *: P<0.001)$; (c) FACS analysis of cells stained for B220, bIgM and $\mathrm{mIgM}$. The numbers in each plot correspond to the cell percentages contained within each gate. The data presented are representative of measurements in at least five individual mice.

immunized with OVA. All of the mice were given a primary injection on day 0 and a second injection on day 14. Serum samples were collected before immunization and 1 week after the second immunization. The samples were used to detect the concentrations of OVA antigenspecific IgG, OVA antigen-specific IgM, total IgM, IgG, IgA and bovine IgM. On average, control mice exhibited 2-, 3.7- and 1.2-fold increases in the concentrations of total IgM, IgG and IgA, respectively (Fig. 5a). The transgenic mice in Line 15 demonstrated 1.3-, 2.2- and 1.27-fold increases in the total concentrations of the three Ig classes (Fig. 5a), though no increase in the concentration of bovine IgM was detected (Fig. 5b). On average, the OVA-specific IgM concentration was about 4.3-fold increases between the immunized Line 15 transgenic mice to the control mice. The OVA-specific IgG concentration was about $3.27 \times 10^{8} \mathrm{U} \cdot \mathrm{mL}^{-1}$ in the immunized control mice but only about $4.76 \times 10^{7} \mathrm{U} \cdot \mathrm{mL}^{-1}$ in the Line 15 transgenic mice, a reduction of approximately 6.87-fold $(P<0.05)$ (Fig. 5b). These data suggest that the transgenic mice were deficient in the ability to mount the specific IgG response.

\subsection{Expression of endogenous $\operatorname{IgL}$ in transgenic mice}

Western blotting using mouse $\lambda$ or $\kappa$ light-chain-specific antibodies revealed an increase in the $\lambda / \kappa$ ratio in the serum of transgenic mice compared to WT mice (Fig. 7a). However, surface staining of the two light chains on splenic B cells revealed similar or even greater $\kappa / \lambda$ ratios in the transgenic mice compared to those in the WT mice (Fig. $7 \mathrm{~b}$ and Fig. 7d). To investigate this apparent discrepancy, the $\kappa / \lambda$ ratios in endogenous mouse IgMand bovine IgM-expressing B cells were further examined and compared to the ratio in IgM-expressing B cells of WT mice. Although bovine IgM-expressing B cells exhibited a similar $\kappa / \lambda$ ratio $(\sim 30)$ to that observed in the mouse IgMexpressing B cells of the WT mice, this ratio was significantly reduced in the mouse IgM-expressing B cells of the transgenic mice (ranging from one-ninth to one-half of the WT mice values) $(P<0.001)$ (Fig. 7c and Fig. 7e). This reduction indicates that a significantly greater percentage of mouse IgM-expressing B cells tended to use $\lambda$ chains in the transgenic mice. Although 
(a)

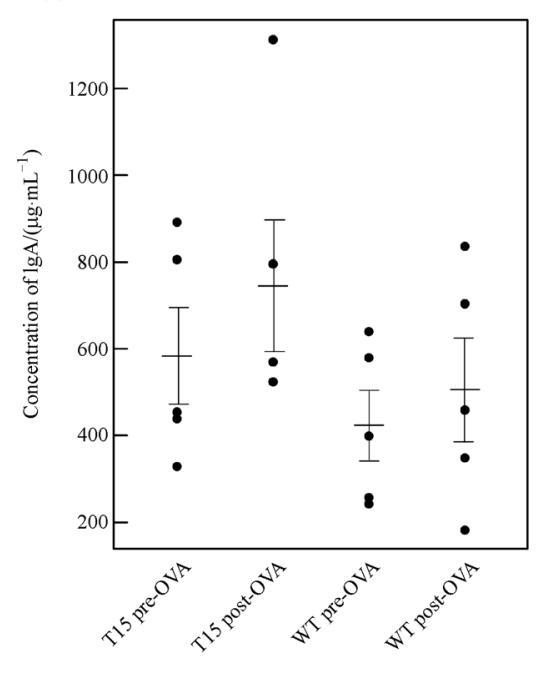

(b)

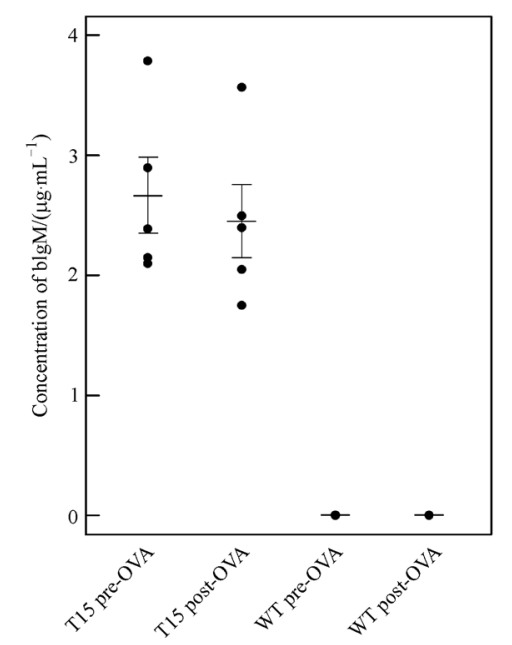

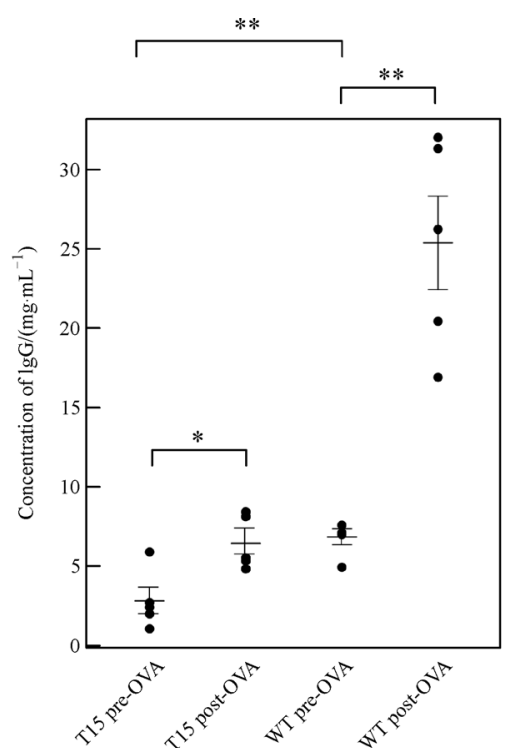
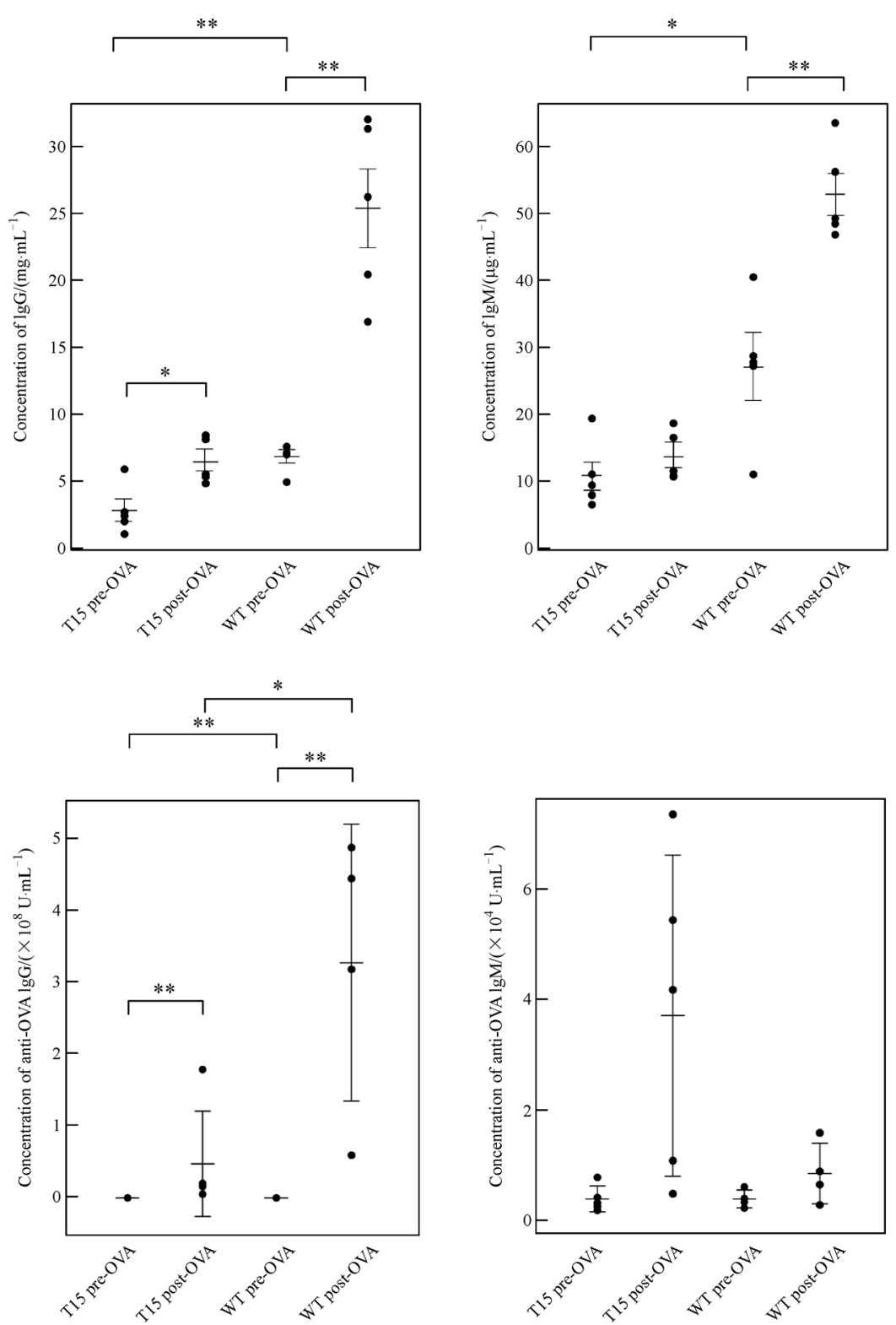

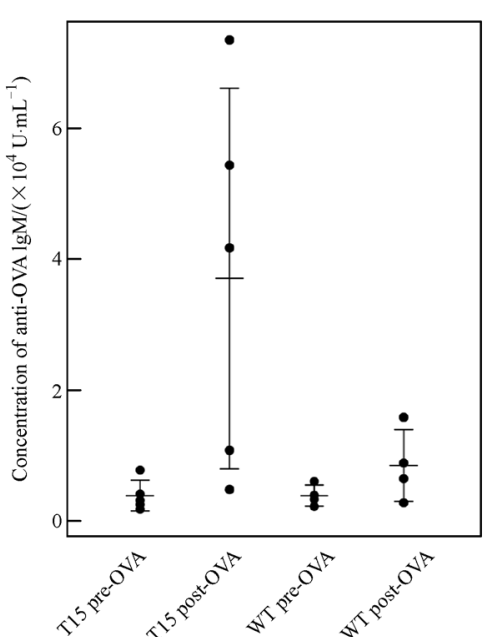

Fig. 5 ELISA measurement of serum Ig concentrations. Serum Ig concentrations were measured both before and after OVA immunization. (a) Concentrations of total endogenous IgA, IgG and IgM; (b) concentrations of bovine IgM, anti-OVA IgM and anti-OVA $\mathrm{IgG}$ in the three groups. Each point represents the antibody concentration in the serum of an individual mouse. The units of Ig content are indicated in each figure. The horizontal bars represent the mean, and the error bars represent the standard error of the mean expression level. $P$ values were analyzed using two-tailed Student $t$ tests $(*: P<0.05, * *: P<0.01)$.

mouse IgM-expressing B cells were far outnumbered by bovine IgM-expressing B cells in the spleen, the former contributed more immunoglobulins in the serum of transgenic mice, as mentioned above. This may explain why the transgenic mice exhibited increased $\lambda / \kappa$ ratios in the serum compared to the WT mice.

3.6 The transgenic bovine VDJ exon is rarely if ever mutated and could be trans-spliced to endogenous IGHC genes

The bovine VDJ sequences expressed in the spleen were amplified and cloned. A total of 47 clones (with inserts of approximately $300 \mathrm{bp}$ ) were sequenced. Of these, eight clones contained a total of ten point mutations, whereas 39 clones contained no mutations. The ten point mutations caused seven different amino acid changes and were not concentrated in the complementarity determining region (CDR) but were evenly distributed within the VDJ exon. It is difficult to judge whether these observed mutations resulted from somatic hypermutation in B cells or PCR errors. Nevertheless, these mutations were mostly A to $G$ transitions and therefore clearly distinct from naturally occurring mutations in bovine $\operatorname{IgH}$ genes [29,30]. No 
Bone marrow
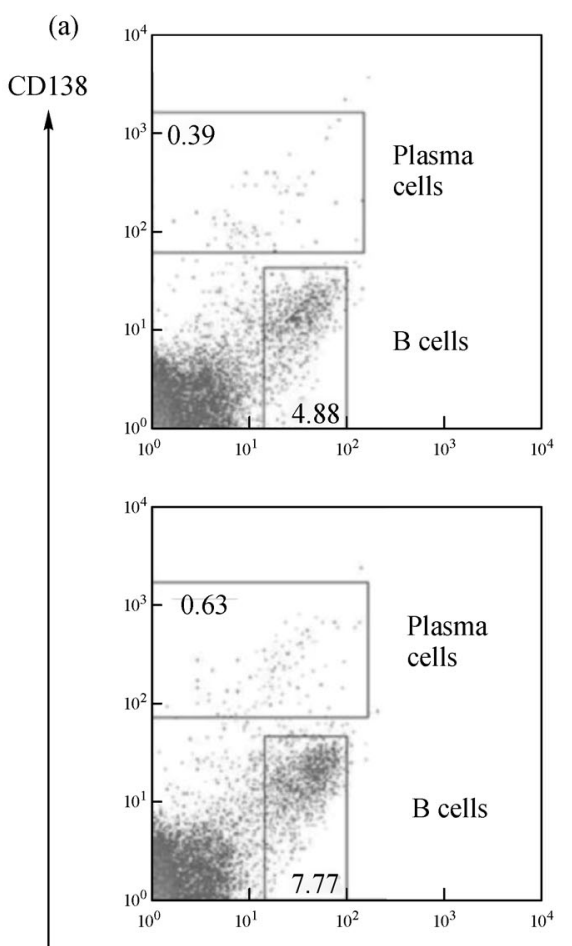

Spleen
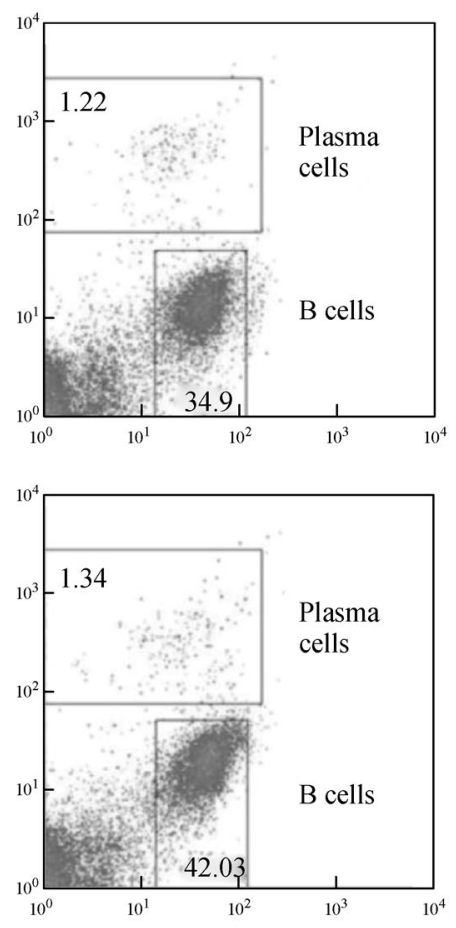

PBLs
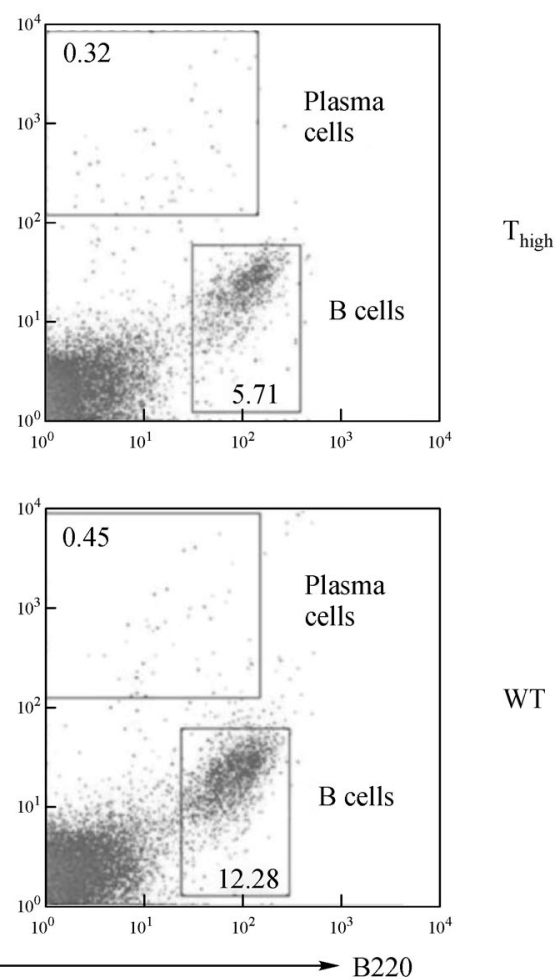

WT (b)

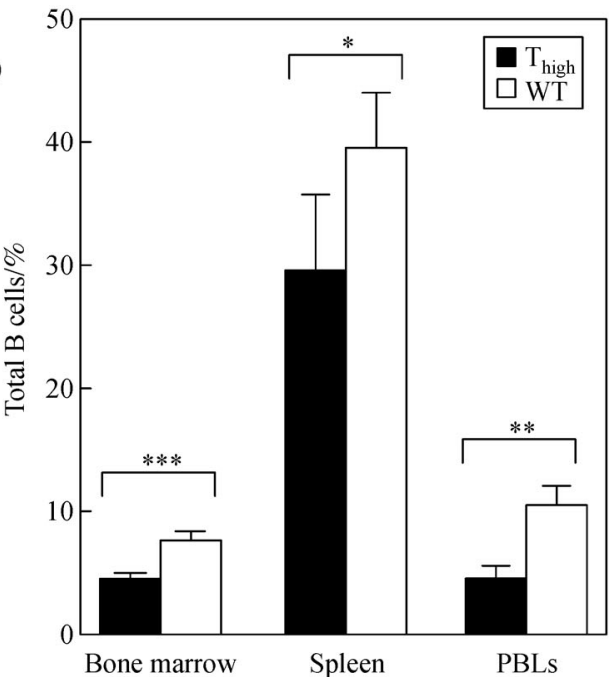

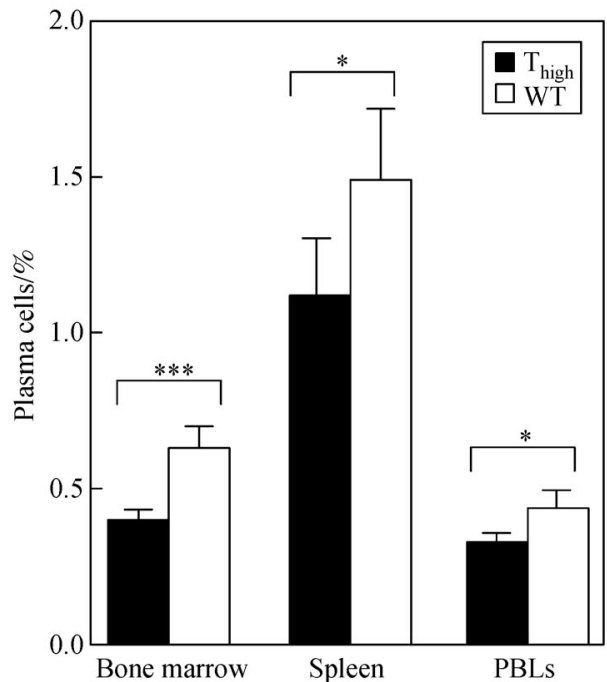

Fig. 6 Flow cytometric analysis of plasma cells and B cells in the bone marrow, spleen and PBL. (a) Gates indicate the plasma cell subset $\left(\mathrm{CD} 138^{+} \mathrm{B} 220^{-}\right)$and the $\mathrm{B}$ cell subset $\left(\mathrm{CD} 138^{-} \mathrm{B} 220^{+}\right)$. The proportion of cells within each gate is indicated in the figure. The plots are representative of measurements in at least five individual mice; (b) statistical analysis of percentages of B cells and plasma cells in various tissues based on the data from subfigure a. $P$ values were analyzed using two-tailed Student $t$ tests $(*: P<0.05, * *: P<0.01, * * *$ : $P<0.001)$.

mutations were located in the RGYW hotspots.

Previous studies have reported that the VDJ exon of transgenic IgH genes can be trans-spliced to endogenous
IGHC genes [31,32]. To assess whether this was possible in the transgenic animals generated here, bovine VDJspecific primers and primers specific to each of the 
(a)
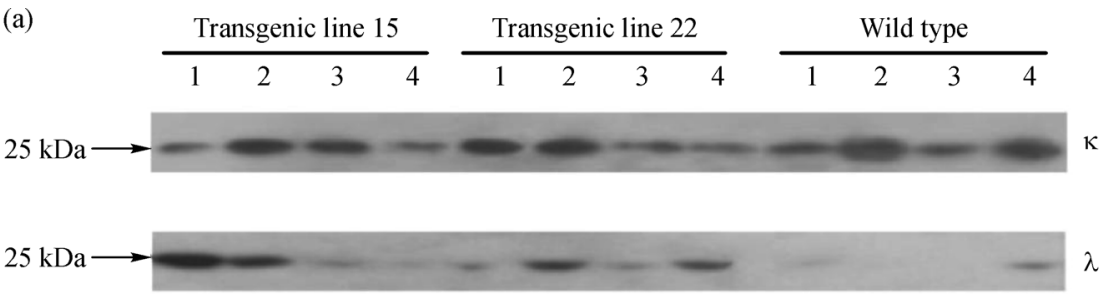

(b)

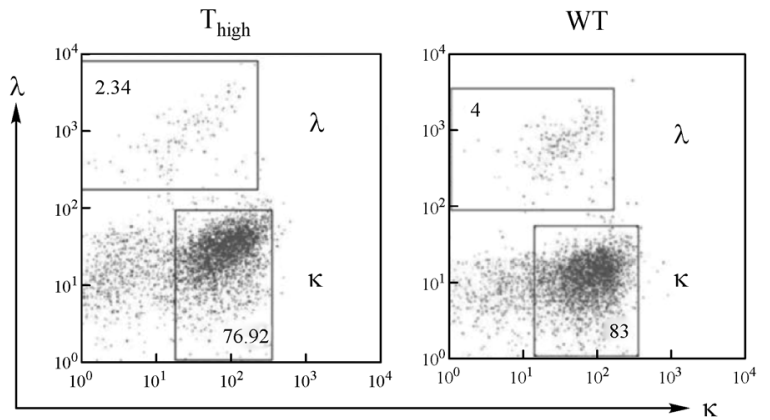

(c)
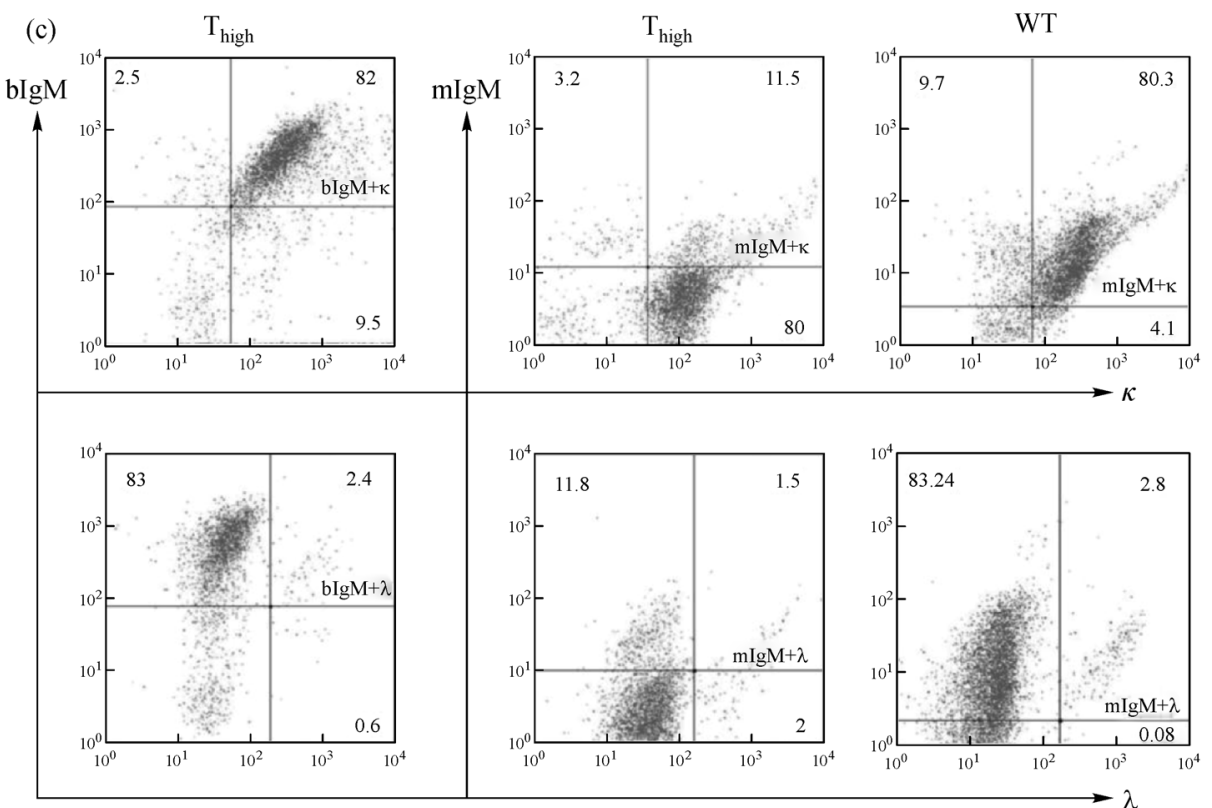

(d)

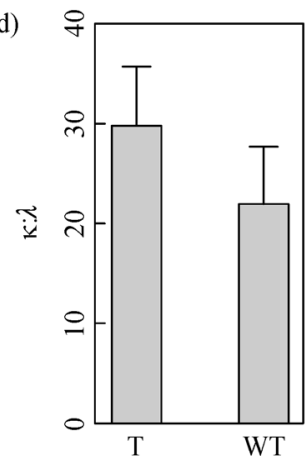

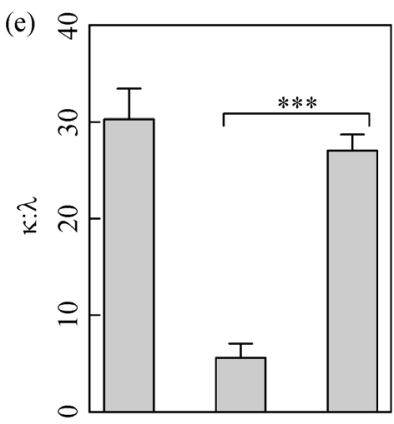

T-bIgM $\kappa / \lambda$ T-mIgM $\kappa / \lambda$ WT-mIgM $\kappa / \lambda$

Fig. 7 Expression analysis of light chains in transgenic $\left(\mathrm{T}_{\text {high }}\right)$ and WT mice. (a) Analysis of mouse $\kappa$ or $\lambda$ light chains in sera by western blotting. Four mice from each group were evaluated; (b) FACS analysis of mouse $\kappa$ and $\lambda$ light chains on splenic B cells; (c) FACS profiles of splenic lymphocytes stained for B220, two types of $\operatorname{IgM}$ and $\kappa$ or $\lambda$. The percentage of each subset is indicated in the appropriate gate. The data presented are representative of at least four individual mice; (d) statistical analysis of $\kappa: \lambda$ ratios based on the data from subfigure b. The ratios of $\kappa$ to $\lambda$ on splenic B cells in transgenic and WT mice are indicated by bars; (e) statistical analysis of $\kappa: \lambda$ ratios based on the data from subfigure $\mathrm{c}$. The ratios of $\kappa$ to $\lambda$ on bovine IgM-expressing B cells and mouse IgM-expressing B cells in transgenic or WT mice are indicated by bars $(* * *: P<0.001)$. 
endogenous IGHC genes were used in one- or two-round RT-PCR using splenic RNA as a template. The bovine VDJ exon was observed to be trans-spliced to the endogenous $\mu$, $\delta, \gamma$ and $\alpha$ genes. Bovine VDJ-C $\alpha$ transcripts were easily detected after even one round of PCR. To exclude the possibility that the trans-spliced transcripts were generated by class-switch recombination (CSR) between the bovine $\mathrm{S} \mu$ and endogenous switch regions (S regions), we used primers derived from the $5^{\prime}$ flanking region of the bovine $\mathrm{S} \mu$ and the $3^{\prime}$ flanking sequences of the endogenous $\mathrm{S}$ region to amplify recombined $\mathrm{S}$ fragments. This amplification proved impossible, leaving trans-splicing as the most plausible explanation for these data.

3.7 The VH and VL repertoire of endogenous Ig genes in transgenic mice

To analyze how the repertoire of endogenous mouse Ig genes was influenced by the expression of the bovine IgM transgene, splenically expressed $\mathrm{VH}, \mathrm{V} \kappa$ and $\mathrm{V} \lambda$ were amplified and sequenced in both transgenic and WT mice. Among $71 \mathrm{VH}$ fragments cloned from WT mice, 63 were found to contain unique CDR3 sequences $(88 \%, 63 / 71)$, each representing an independent VDJ recombination event (Table 1). The ratio was reduced to $74 \%$ (57/77, $P<0.05)$ in Line 22 and 48\% $(42 / 87, P<0.001)$ in Line 15 , indicating that the VDJ recombination of endogenous mouse IgH was inhibited by the transgene (Table 1). This observation is consistent with the flow cytometry data. The $\mathrm{VJ}$ recombination of the $\kappa$ light chain was only slightly affected, if at all. The observed ratios of 59\% (56/94) in Line 15 and 67\% (62/92) in Line 22 were not significantly different from the ratio of 69\% (65/94) in WT mice (Table 1). However, the VJ recombination events for the $\lambda$ light chain were markedly increased in the transgenic mice $(24 \%, 19 / 78$ in Line 15, $P<0.001$; and 13\%, 11/83 in Line $22, P<0.05)$ compared to the WT mice, in which only three unique CDR3 sequences were observed in 86 cloned $\mathrm{V} \lambda$ fragments (approximately 3\%) (Table 1). Despite these changes, the CDR3 length and the number of nontemplated $(\mathrm{N})$ and palindromic $(\mathrm{P})$ nucleotides in the $\mathrm{V}$ (D)J junctions of $\mathrm{VH}, \mathrm{V} \kappa$ and $\mathrm{V} \lambda$ were not markedly different between transgenic and WT mice (Table 1).

To analyze the repertoire of endogenous Ig genes in the bovine IgM-expressing B cells $\left(\mathrm{bIgM}^{+}\right)$and mouse IgMexpressing $\mathrm{B}$ cells $\left(\mathrm{mIgM}^{+}\right)$of the transgenic mice, the $\mathrm{bIgM}^{+}$and $\mathrm{mIgM}^{+}$cells in the spleen from one transgenic line were sorted by flow cytometry, respectively. Then $\mathrm{VH}$, $\mathrm{V} \kappa$ and $\mathrm{V} \lambda$ were amplified and sequenced in both transgenic and WT mice. Among $64 \mathrm{VH}$ fragments cloned from transgenic mice, 26 were found to contain unique CDR3 sequences $(41 \%, 26 / 64, P<0.001)$, each representing an independent VDJ recombination event (Table 2). For $\kappa$ light chain, the ratios of $46 \%(34 / 74, P<0.05)$ in $\mathrm{mIgM}^{+}$cells and $59 \%(63 / 107)$ in bIgM $^{+}$cells were observed in the transgenic mice, which is different from the ratio of 69\% (65/94) in WT mice (Table 2). While the VJ recombination events for the $\lambda$ light chain were markedly increased in the $\mathrm{bIgM}^{+}$cells $(28 \%, 17 / 61, P<0.001)$ compared to the WT mice(Table 2), we could not amplified $\mathrm{V} \lambda$ from the $\mathrm{mIgM}^{+}$cells, possibly because $\lambda$ light chain rarely expressed in these positive cells. The same as our previous analysis results, the CDR3 length and the number of non-templated $(\mathrm{N})$ and palindromic $(\mathrm{P})$ nucleotides in the $\mathrm{V}(\mathrm{D}) \mathrm{J}$ junctions of $\mathrm{VH}, \mathrm{V} \kappa$ and $\mathrm{V} \lambda$ were not markedly different between IgM positive cells(bovine IgM or mouse $\operatorname{IgM})$ in the transgenic and WT mice.

Frequency analyses of the usage of specific variable (V), diversity (D) and joining (J) gene segments in the clones revealed some consistent differences between transgenic and WT mice. For instance, the use of the immunoglobulin heavy chain variable gene family 7 (IGHV7), immunoglobulin heavy chain diversity gene family 2 (IGHD2), immunoglobulin heavy chain joining gene family 3 (IGHJ3), immunoglobulin $\kappa$ chain variable gene family 1 (IGKV1) and immunoglobulin $\lambda$ chain variable gene family 1 (IGLV1) members was greatly increased in the transgenic mice, whereas the opposite was found for IGHV8, IGHV14, IGHD4, IGKV12 and immunoglobulin $\lambda$ chain joining gene family 2 (IGLJ2) members [2].

\section{Discussion}

In this study, transgenic mice expressing bovine $\operatorname{IgM}$ at high levels were produced. To our knowledge, these are the first transgenic mice that have been developed to express bovine IgM. These mice analyzed results showed that (1) the $\mathrm{DH}$ and $\mathrm{JH}$ segments derived from the duplicated locus on BTA 11 were able to undergo rearrangement, (2) bovine IgM was able to mediate allelic exclusion in mice, (3) the expression of bovine IgM led to a reduced proportion of pro- and pre-B cells but an increased proportion of immature B cells, (4) bovine IgM-expressing $\mathrm{B}$ cells were able to migrate from the bone marrow to peripheral lymphoid tissues, but most of them were blocked at the T1 transitional stage and could not develop into mature B cells, (5) the animals were deficient in the specific IgG antibody response, and (6) the endogenous Ig repertoire was altered by bovine IgM expression.

IgM is an ancient, structurally conserved Ig class that is expressed by all jawed vertebrates [1,2]. It is also the first surface Ig expressed on the B cells that can drive further B cell differentiation. IgM heavy chain constant regions in different mammals, such as cattle, humans and mice, differ by as much as $40 \%$ in amino-acid sequence although transmembrane domains are nearly identical. It has previously been reported that the human $\operatorname{IgM}$ gene is functional in both mice and cattle [13,24]. In this study, we demonstrated that the bovine IgM gene was able to mediate allelic exclusion in mice in spite of significant structural and sequence differences. High levels of bovine 
Table 1 Analysis of CDR3 length and number of N and P nucleotides in transgenic and WT mice

\begin{tabular}{|c|c|c|c|c|c|c|c|c|c|c|}
\hline & \multicolumn{4}{|c|}{ IGH } & \multicolumn{3}{|c|}{ IGK } & \multicolumn{3}{|c|}{ IGL } \\
\hline & Unique/Total & CDR3 & D $5^{\prime} \mathrm{N}+\mathrm{P}$ & $\mathrm{D} 3^{\prime} \mathrm{N}+\mathrm{P}$ & Unique/Total & CDR3 & $\mathrm{N}+\mathrm{P}$ & Unique/Total & CDR3 & $\mathrm{N}+\mathrm{P}$ \\
\hline WT & $\begin{array}{l}63 / 71 \\
(88 \%)\end{array}$ & $10.89 \pm 3.03$ & $3.11 \pm 3.26$ & $1.51 \pm 2.33$ & $\begin{array}{l}65 / 94 \\
(69 \%)\end{array}$ & $8.95 \pm 0.51$ & $0.50 \pm 1.64$ & $\begin{array}{c}3 / 86 \\
(3.5 \%)\end{array}$ & $11.00 \pm 2.00$ & 0 \\
\hline $\mathrm{T} 15$ & $\begin{array}{c}42 / 87 \\
(48 \%)^{* * *}\end{array}$ & $10.45 \pm 2.62$ & $2.00 \pm 2.85$ & $1.48 \pm 2.03$ & $\begin{array}{l}56 / 94 \\
(59 \%)\end{array}$ & $8.91 \pm 0.39$ & $0.18 \pm 0.77$ & $\begin{array}{c}19 / 78 \\
(24 \%)^{* * *}\end{array}$ & $10.00 \pm 1.67$ & $0.26 \pm 0.73$ \\
\hline T22 & $\begin{array}{c}57 / 77 \\
(74 \%)^{*}\end{array}$ & $11.11 \pm 2.94$ & $2.26 \pm 3.23$ & $2.35 \pm 3.06$ & $\begin{array}{l}62 / 92 \\
(67 \%)\end{array}$ & $9.02 \pm 0.46$ & $0.16 \pm 0.76$ & $\begin{array}{c}11 / 83 \\
(13 \%)^{*}\end{array}$ & $11.44 \pm 1.94$ & $0.75 \pm 1.04$ \\
\hline
\end{tabular}

Note: The ratios of unique to total numbers are listed in the table and assessed by Chi-square tests between transgenic and WT groups $\left({ }^{*}: P<0.05, * * *: P<0.001\right)$. N nucleotides $(\mathrm{N})$ : non-templated nucleotides; P nucleotides $(\mathrm{P})$ : palindromic nucleotides.

Table 2 Analysis of CDR3 length and number of $\mathrm{N}$ and $\mathrm{P}$ nucleotides in IgM positive cells of transgenic and WT mice

\begin{tabular}{|c|c|c|c|c|c|c|c|c|c|c|}
\hline & \multicolumn{4}{|c|}{ IGH } & \multicolumn{3}{|c|}{ IGK } & \multicolumn{3}{|c|}{ IGL } \\
\hline & Unique/Total & CDR3 & $5^{\prime} \mathrm{N}+\mathrm{P}$ & $3^{\prime} \mathrm{N}+\mathrm{P}$ & Unique/Total & CDR3 & $\mathrm{N}+\mathrm{P}$ & Unique/Total & CDR3 & $\mathrm{N}+\mathrm{P}$ \\
\hline$\overline{\mathrm{WT}}$ & $\begin{array}{l}63 / 71 \\
(88 \%)\end{array}$ & $10.89 \pm 3.03$ & $3.11 \pm 3.26$ & $1.51 \pm 2.33$ & $\begin{array}{l}65 / 94 \\
(69 \%)\end{array}$ & $8.95 \pm 0.51$ & $0.50 \pm 1.64$ & $\begin{array}{c}3 / 86 \\
(3.5 \%)\end{array}$ & $11.00 \pm 2.00$ & 0 \\
\hline $\mathrm{mIgM}$ & $\begin{array}{c}26 / 64 \\
(48 \%)^{* * *}\end{array}$ & $10.70 \pm 2.36$ & $2.22 \pm 2.61$ & $1.52 \pm 2.57$ & $\begin{array}{c}34 / 74 \\
(46 \%)^{*}\end{array}$ & $7.85 \pm 0.31 *$ & $0.09 \pm 0.29 * * *$ & & & \\
\hline bIgM & & & & & $\begin{array}{l}63 / 107 \\
(59 \%)\end{array}$ & $8.54 \pm 0.37^{*}$ & $0.37 \pm 1.56$ & $\begin{array}{c}17 / 61 \\
(28 \%)^{* * *}\end{array}$ & $10.75 \pm 2.01$ & $0.35 \pm 0.86^{* * *}$ \\
\hline
\end{tabular}

Note: The ratios of unique to total numbers are listed in the table and assessed by Chi-square tests between transgenic and WT groups $(*: P<0.05, * * *: P<0.001)$. $\mathrm{N}$ nucleotides $(\mathrm{N})$ : non-templated nucleotides; $\mathrm{P}$ nucleotides $(\mathrm{P})$ : palindromic nucleotides.

IgM expression largely inhibited the expression of endogenous mouse IgM, and bovine IgM-expressing B cells were able to undergo development in the bone marrow and migrate to peripheral lymphoid tissues. As SLC encoding genes have also been identified in cattle [33], it is therefore highly likely that the bovine IgM heavy chain can form pre-BCR or BCR complexes with the mouse SLC or conventional light chain and $\operatorname{Ig} \alpha / \operatorname{Ig} \beta$ on the mouse $\mathrm{B}$ cells, and this bovine IgM pre-BCR may provide feedback signals to inhibit VDJ rearrangement at the endogenous IgH locus. However, as recent studies have revealed that feedback inhibition by pre-BCR may not be the only mechanism responsible for IgH allelic exclusion [12], it is also possible that the bovine IgM heavy chain alone could mediate allelic exclusion, given that it does not bind the mouse SLC to form pre-BCR. In this regard, it would be interesting to investigate whether the mouse VpreB and 15 are present on the surface of the bovine IgM expressing B cells at their early developmental stages.

As shown in Fig. 4c, approximately $9.2 \%$ of splenic and $5.4 \%$ of blood B cells in transgenic mice expressed both bovine IgM and murine IgM on their surfaces, so it seems that the expression of bovine IgM does not exert stringent allelic exclusion. It is unlikely that this arises because of the bovine sequence of the transgene. Similar phenomena have been observed in previous studies of Ig transgenic mice $[31,32,34,35]$. In these cases, as in the report presented here, the proportion of B cells that express two heavy chains far exceeds that observed in WT mice (approximately $0.01 \%$ of double heavy-chain-producing cells) [36]. This high frequency of allelic inclusion has several possible explanations: (1) similar to previously reported studies [31,32], RNA trans-splicing between transgene and endogenous IGHC genes is responsible for the production of these double heavy-chain-producing cells. Indeed, we could detect trans-splicing events between bovine VDJ exon and endogenous IGHC genes in the transgenic mice reported in this study; (2) it is also likely that during the development of these double producers, the expression of the bovine IgM occurred after the VDJ rearrangement and expression of the endogenous mouse IgM; (3) allelic exclusion could be far more complex than a simple feedback mechanism initiated by an expressed heavy chain and may involve many factors, such as enhancers, the chromosomal positioning of the $\operatorname{IgH}$ locus or the amount of $\operatorname{IgH}$ expressed in a given $\mathrm{B}$ cell.

In the transgenic mice that expressed bovine $\operatorname{IgM}$ at high levels, most bovine IgM-expressing B cells were blocked at the $\mathrm{T} 1$ transitional stage, though they were able to migrate to peripheral lymphoid tissues from the bone marrow. Consequently, mature B cells were largely reduced in these mice. Similar observations have been reported for other Ig transgenic mice and rabbits $[18,19]$. However, Herzenberg et al. failed to perform a detailed characterization of the $\mathrm{B}$ cell populations in their transgenic mice [18]. Thus, it was difficult to judge at which stage B cell development was terminated, though a reduction in the pre-B cell population was noted. In $\operatorname{IgH}$ transgenic rabbits, the presence of the foreign $\operatorname{IgH}$ 
transgene prevented the transition from large (early) pre-B to small (late) pre-B cells [19]. In both examples, the transgenic animal lines were created with transgenes derived from the homologous species. In our transgenic mice, the transgene was of bovine origin. Although the pro- and pre-B cell populations were reduced by 2- to 3fold, the immature B cell (expressing bovine IgM) population was increased by 2 - to 3 -fold compared to that of WT mice. These observations suggest that the forced expression of bovine IgM facilitated the development of B cells to an immature stage in the bone marrow and that the B cell developmental defect occurred in the peripheral lymphoid tissues but not in the bone marrow.

It is not yet clear why most of the bovine IgMexpressing B cells were blocked at the T1 stage. Given that both $\mathrm{T} 2$ and mature $\mathrm{B}$ cells express $\mathrm{IgD}$ on their surface while T1 B cells do not [28], it is possible that the expression of $\operatorname{IgD}$ is involved in $\mathrm{B}$ cell development in two different ways. First, it is possible that surface $\operatorname{IgD}$ expression is necessary for B cell development to the T2 and mature stages. The bovine IgM-expressing B cells should not be able to develop to the T2 and mature stages because bovine $\operatorname{IgM}$ inhibits the expression of the endogenous $\operatorname{IgH}$ genes and therefore inhibits the expression of mouse IgD. However, this does not appear to be the case. Most B cells could develop to a mature stage in IgDdeficient mice, though the total number of B cells was reduced $[37,38]$. Furthermore, it is possible that surface $\mathrm{IgD}$ expression is an outcome of $\mathrm{B}$ cell development. In normal mice, each stage of B cell development is associated with specific molecular signals, which in turn drive the next stage of development. Foreign transgenes may not be able to initiate the proper signals in a given developmental stage. The presence of a pseudo- $\delta$ gene on the transgene used in our experiments is also of potential relevance. Thus, the activation of the endogenous $\operatorname{IgH}$ locus as a whole (not only the expression of $\operatorname{IgM}$ ) may be required to initiate certain developmental signal(s) that could not be triggered by the artificial, transgenic $\operatorname{IgH}$ genes. Alternatively, because each transgenic IgH gene enforces the expression of only one $\mathrm{IgH}$, the products of different transgenes may differ in the strength of their pairing with the SLC or conventional light chains, thus resulting in variable signal identity or strength. This may explain why B cells were blocked at different developmental stages in different IgH transgenic animals.

Independent of the above speculations, there is another possibility that may also partially explain why bovine IgMexpressing $\mathrm{B}$ cells were arrested at the $\mathrm{T} 1$ stage. In mammals, the expression ratios of $\lambda / \kappa$ light chains vary considerably across species. For example, the ratio is approximately $95 / 5$ in cattle, but it is $40 / 60$ in humans and $5 / 95$ in mice [39]. These widely varying ratios are, apart from the relative complexity of two light chain germline repertoires, an outcome of endogenous selection to restrict self-reactivity in different species [39]. It is also known that negative selection of self-reactive immature B cells can occur at the T1 stage in addition to in the bone marrow [40]. In this regard, there might be a preference for bovine IgM pairing with $\lambda$ chains, and most $B$ cells expressing bovine IgM and mouse $\kappa$ chains may not be able to pass the selection at the T1 stage.

Compared with WT mice, it is surprisingly that the transgenic mice showed slightly increased IgA levels, although both endogenous IgM and IgG were decreased in the serum. This finding is somewhat consistent with a previous report that IgA production could be detected in $\mu \mathrm{MT}$ mice, which expressed no $\operatorname{IgM}$ and $\operatorname{IgG}$ [41], supporting the presence of an IgM-independent pathway for IgA production [41]. Possibly, this pathway may be ascribed to RNA trans-splicing. If so, it would be interesting to figure out why only $\operatorname{IgA}$, but not other non-IgM/IgD isotypes are involved.

A significantly reduction of VDJ recombination event was found in mouse IgM-expressing B cells of the transgenic mice when compared to that of the WT mice, indicating that endogenous $\operatorname{IgH}$ rearrangement was inhibited by the transgene. It is also worth noting that the proportion of $\lambda$ light chain-containing immunoglobulins was elevated in the serum of the transgenic mice. This is consistent with the fact that the $\lambda$ chain repertoire was significantly increased in the transgenic mice, while the $\kappa$ chain repertoire remained comparable to that of the WT mice. However, the Vк repertoire of mouse IgM-expressing cells from spleen was reduced in the transgenic mice. while a significantly higher ratio of mouse IgM-expressing B cells tended to use $\lambda$ chains when compared to those of the WT mice. Although it is unclear why this occurred, the mouse IgM-expressing B cells constituted a majority of the mature B cell population and thus the plasma cell population and serum Ig levels as well.

\section{Conclusions}

Although a number of $\operatorname{IgH}$ transgenic mice have been previously studied, both similar and distinct characteristics have been reported in these genetic models compared to our mice. Our experiments show that functional rearrangement of the DH and JH segments present on BTA 11 can take place, but of wider significance, that allelic exclusion at the IgH locus can be driven by expression of a heterologous IgM construct. A thorough analysis of B cell development in these mice is still needed to gain further insight into underlying regulatory mechanisms.

Acknowledgements The authors want to thank Liying Du for technical help with flow cytometry, Dr. Xiaorong Gu for help with statistical analysis and Prof. Lennart Hammarstrom for critical reading of the manuscript. This work was supported by the National Science Fund for Distinguished Young Scholars (30725029), the National Basic Research Program of China (2010CB945300). 
Supplementary materials The online version of this article at http://dx. doi.org/10.15302/J-FASE-2014015 contains supplementary materials (Appendix A and B).

Compliance with ethics guidelines Min Zhang, Xueqian Cheng, Dan Chu, Jingwen Liang, Yi Sun, Li Ma, Beilei Xu, Min Zheng, Meili Wang, Liming Ren, Xiaoxiang Hu, Qingyong Meng, Ran Zhang, Ying Guo, Yunping Dai, Robert Aitken, Ning Li and Yaofeng Zhao declare that they have no conflict of interest or financial conflicts to disclose.

All applicable institutional and national guidelines for the care and use of animals were followed.

\section{References}

1. Flajnik M F. Comparative analyses of immunoglobulin genes: surprises and portents. Nature Reviews-Immunology, 2002, 2(9): 688-698

2. Flajnik M F, Kasahara M. Origin and evolution of the adaptive immune system: genetic events and selective pressures. Nature Reviews-Genetics, 2010, 11(1): 47-59

3. Matthias P, Rolink A G. Transcriptional networks in developing and mature B cells. Nature Reviews-Immunology, 2005, 5(6): 497-508

4. Yancopoulos G D, Blackwell T K, Wood C, Thomas E, Boss M, Coffman R, Rosenberg N, Tonegawa S, Baltimore D. EMBO Journal, 1984, 3(6): 1209-1219

5. ten Boekel E, Melchers F, Rolink A G. Precursor B cells showing H chain allelic inclusion display allelic exclusion at the level of pre-B cell receptor surface expression. Immunity, 1998, 8(2): 199-207

6. Keyna U, Beck-Engeser G B, Jongstra J, Applequist S E, Jäck H M. Surrogate light chain-dependent selection of Ig heavy chain $\mathrm{V}$ regions. Journal of Immunology, 1995, 155(12): 5536-5542

7. Kline G H, Hartwell L, Beck-Engeser G B, Keyna U, Zaharevitz S, Klinman N R, Jäck H M. Pre-B cell receptor-mediated selection of pre-B cells synthesizing functional mu heavy chains. Journal of Immunology, 1998, 161(4): 1608-1618

8. Melchers F. The pre-B-cell receptor: selector of fitting immunoglobulin heavy chains for the B-cell repertoire. Nature ReviewsImmunology, 2005, 5(7): 578-584

9. Pernis B, Chiappino G, Kelus A S, Gell P G. Cellular localization of immunoglobulins with different allotypic specificities in rabbit lymphoid tissues. The Journal of Experimental Medicine, 1965, 122 (5): $853-876$

10. Weiler E. Differential activity of allelic gamma-globulin genes in antibody-producing cells. Proceedings of the National Academy of Sciences of the United States of America, 1965, 54(6): 1765-1772

11. Vettermann C, Schlissel M S. Allelic exclusion of immunoglobulin genes: models and mechanisms. Immunological Reviews, 2010, 237 (1): $22-42$

12. Lutz J, Heideman M R, Roth E, van den Berk P, Müller W, Raman C, Wabl M, Jacobs H, Jäck H M. Pro-B cells sense productive immunoglobulin heavy chain rearrangement irrespective of polypeptide production. Proceedings of the National Academy of Sciences of the United States of America, 2011, 108(26): 1064410649

13. Nussenzweig M C, Shaw A C, Sinn E, Danner D B, Holmes K L, Morse H C 3rd, Leder P. Allelic exclusion in transgenic mice that express the membrane form of immunoglobulin mu. Science, 1987,
236(4803): 816-819

14. Rusconi S, Köhler G. Transmission and expression of a specific pair of rearranged immunoglobulin mu and kappa genes in a transgenic mouse line. Nature, 1985, 314(6009): 330-334

15. Weaver D, Costantini F, Imanishi-Kari T, Baltimore D. A transgenic immunoglobulin mu gene prevents rearrangement of endogenous genes. Cell, 1985, 42(1): 117-127

16. Roth P E, Doglio L, Manz J T, Kim J Y, Lo D, Storb U. Immunoglobulin gamma $2 \mathrm{~b}$ transgenes inhibit heavy chain gene rearrangement, but cannot promote B cell development. The Journal of Experimental Medicine, 1993, 178(6): 2007-2021

17. Nussenzweig M C, Shaw A C, Sinn E, Campos-Torres J, Leder P. Allelic exclusion in transgenic mice carrying mutant human IgM genes. The Journal of Experimental Medicine, 1988, 167(6): 19691974

18. Herzenberg L A, Stall A M, Braun J, Weaver D, Baltimore D, Herzenberg L A, Grosschedl R. Depletion of the predominant B-cell population in immunoglobulin mu heavy-chain transgenic mice. Nature, 1987, 329(6134): 71-73

19. Jasper P J, Rhee K J, Kalis S L, Sethupathi P, Yam P C, Zhai S K, Knight K L. B lymphocyte deficiency in IgH-transgenic rabbits. European Journal of Immunology, 2007, 37(8): 2290-2299

20. Zhao Y, Kacskovics I, Pan Q, Liberles D A, Geli J, Davis S K, Rabbani H, Hammarstrom L. Artiodactyl IgD: the missing link. Journal of Immunology, 2002, 169(8): 4408-4416

21. Tobin-Janzen T C, Womack J E. Comparative mapping of IGHG1, IGHM, FES, and FOS in domestic cattle. Immunogenetics, 1992, 36 (3): $157-165$

22. Hayes H C, Petit E J. Mapping of the beta-lactoglobulin gene and of an immunoglobulin $\mathrm{M}$ heavy chain-like sequence to homoeologous cattle, sheep, and goat chromosomes. Mammalian Genome, 1993, 4 (4): 207-210

23. Zhao Y, Kacskovics I, Rabbani H, Hammarstrom L. Physical mapping of the bovine immunoglobulin heavy chain constant region gene locus. Journal of Biological Chemistry, 2003, 278(37): 3502435032

24. Kuroiwa Y, Kasinathan P, Sathiyaseelan T, Jiao J A, Matsushita H, Sathiyaseelan J, Wu H, Mellquist J, Hammitt M, Koster J, Kamoda S, Tachibana K, Ishida I, Robl J M. Antigen-specific human polyclonal antibodies from hyperimmunized cattle. Nature Biotechnology, 2009, 27(2): 173-181

25. Eggen A, Gautier M, Billaut A, Petit E, Hayes H, Laurent P, Urban C, Pfister-Genskow M, Eilertsen K, Bishop M D. Construction and characterization of a bovine BAC library with four genomeequivalent coverage. Genetics Selection Evolution, 2001, 33(5): 543-548

26. Hosseini A, Campbell G, Prorocic M, Aitken R. Duplicated copies of the bovine $\mathrm{JH}$ locus contribute to the Ig repertoire. International Immunology, 2004, 16(6): 843-852

27. Loder F, Mutschler B, Ray R J, Paige C J, Sideras P, Torres R, Lamers M C, Carsetti R. B cell development in the spleen takes place in discrete steps and is determined by the quality of B cell receptor-derived signals. The Journal of Experimental Medicine, 1999, 190(1): 75-89

28. Carsetti R, Rosado M M, Wardmann H. Peripheral development of B cells in mouse and man. Immunological Reviews, 2004, 197(1): 
$179-191$

29. Koti M, Kataeva G, Kaushik A K. Novel atypical nucleotide insertions specifically at VH-DH junction generate exceptionally long CDR3H in cattle antibodies. Molecular Immunology, 2010, 47 (11-12): 2119-2128

30. Kaushik A K, Kehrli M E Jr, Kurtz A, Ng S, Koti M, Shojaei F, Saini S S. Somatic hypermutations and isotype restricted exceptionally long CDR3H contribute to antibody diversification in cattle. Veterinary Immunology and Immunopathology, 2009, 127(1-2): $106-113$

31. Shimizu A, Nussenzweig M C, Mizuta T R, Leder P, Honjo T. Immunoglobulin double-isotype expression by trans-mRNA in a human immunoglobulin transgenic mouse. Proceedings of the National Academy of Sciences of the United States of America, 1989, 86(20): 8020-8023

32. Shimizu A, Nussenzweig M C, Han H, Sanchez M, Honjo T. Transsplicing as a possible molecular mechanism for the multiple isotype expression of the immunoglobulin gene. The Journal of Experimental Medicine, 1991, 173(6): 1385-1393

33. Ekman A, Niku M, Liljavirta J, Iivanainen A. Bos taurus genome sequence reveals the assortment of immunoglobulin and surrogate light chain genes in domestic cattle. BMC Immunology, 2009, 10(1): 22-32

34. Stall A M, Kroese F G, Gadus F T, Sieckmann D G, Herzenberg L A, Herzenberg L A. Rearrangement and expression of endogenous immunoglobulin genes occur in many murine B cells expressing transgenic membrane IgM. Proceedings of the National Academy of
Sciences of the United States of America, 1988, 85(10): 35463550

35. Forni L. Extensive splenic B cell activation in IgM-transgenic mice. European Journal of Immunology, 1990, 20(5): 983-989

36. Barreto V, Cumano A. Frequency and characterization of phenotypic Ig heavy chain allelically included IgM-expressing B cells in mice. Journal of Immunology, 2000, 164(2): 893-899

37. Roes J, Rajewsky K. Immunoglobulin D (IgD)-deficient mice reveal an auxiliary receptor function for $\operatorname{IgD}$ in antigen-mediated recruitment of B cells. The Journal of Experimental Medicine, 1993, 177(1): 45-55

38. Nitschke L, Kosco M H, Köhler G, Lamers M C. Immunoglobulin D-deficient mice can mount normal immune responses to thymusindependent and -dependent antigens. Proceedings of the National Academy of Sciences of the United States of America, 1993, 90(5): 1887-1891

39. Knott J, Bona C, Kaushik A. The primary antibody repertoire of $\kappa-$ deficient mice is characterized by non-stochastic $\mathrm{V} \lambda 1+\mathrm{VH}$ gene family pairings and a higher degree of self-reactivity. Scandinavian Journal of Immunology, 1998, 48(1): 65-72

40. Khan W N. B cell receptor and BAFF receptor signaling regulation of B cell homeostasis. Journal of Immunology, 2009, 183(6): 35613567

41. Macpherson A J, Lamarre A, McCoy K, Harriman G R, Odermatt B, Dougan G, Hengartner H, Zinkernagel R M. IgA production without $\mathrm{mu}$ or delta chain expression in developing B cells. Nature Immunology, 2001, 2(7): 625-631 